Research Article

\title{
Optimal Design of Mega-Frame Core Wall Structures Equipped with Viscous Damped Outriggers for Human Comfort Performance under Wind Loading
}

\author{
Yue Yang $\mathbb{D}^{1},{ }^{1}$ Xin Zhao $\mathbb{D}^{2},{ }^{2}$ Weixing Shi $\mathbb{D},{ }^{1}$ and Jiayue $\mathrm{Li} \mathbb{D}^{2}$ \\ ${ }^{1}$ Department of Disaster Mitigation for Structures, Tongji University, Siping Road No. 1239, Shanghai 200092, China \\ ${ }^{2}$ Department of Structural Engineering, Tongji Architectural Design (Group) Co., Ltd., Tongji University, Siping Road No. 1239, \\ Shanghai 200092, China
}

Correspondence should be addressed to Yue Yang; 1610204@tongji.edu.cn

Received 21 October 2020; Revised 3 March 2021; Accepted 12 April 2021; Published 1 June 2021

Academic Editor: Fabio Minghini

Copyright (c) 2021 Yue Yang et al. This is an open access article distributed under the Creative Commons Attribution License, which permits unrestricted use, distribution, and reproduction in any medium, provided the original work is properly cited.

Megatall and supertall buildings often adopt megastructure systems characterized by secondary structure systems, and the serviceability problem caused by wind-induced vibrations often becomes the dominant factor in the structural design. Because the deformation of a supertall building usually presents bending characteristics, a viscous damped outrigger can reduce the windinduced vibration of a supertall building with the installation of a small number of viscous dampers. However, time history analysis of the prototype model considering the nonlinear characteristics of viscous dampers is time-consuming, which is not conducive for iterative design optimization. Additionally, the conventional simplified model composed of one cantilever beam cannot be used for the analysis and design of a viscous damped outrigger. In this study, a simplified wind-induced vibration prediction model is proposed based on the mechanical characteristics of megastructures. This simplified model is a plane model that includes both core walls and frames whose member size can be extracted from the original structure. Parametric analysis shows that the simplified model has high acceleration prediction accuracy. An optimal design method combined with the simplified model, which aims to minimize the damped outrigger system cost, is proposed. A 600-m supertall building is presented as a case study. The accuracy and effectiveness of the simplified model and the optimal design method proposed in this study are illustrated. Thus, applying this optimal design method in combination with the simplified model can save significant analysis and design time and is conducive to the application of viscous damped outriggers in practical engineering.

\section{Introduction}

The prevalent structure system adopted in supertall $(>300 \mathrm{~m})$ and megatall $(>600 \mathrm{~m})$ buildings is the megaframe core wall structure system, where the mega-frame is characterized by a secondary system $[1,2]$. This type of structure system is often accompanied by damped outriggers because as the height increases, the wind-induced horizontal vibration acceleration at the top of the structure is more likely to exceed the code provisions; this is the wind-induced human comfort problem of tall buildings [1-6]. There are two methods to solve the problem of the wind-induced vibration comfort of structures, namely, adjusting the dynamic characteristics of the structure or adopting energy dissipation and vibration reduction schemes. The vibration reduction schemes used to control the wind vibration include tuned damping schemes with a tuned mass damper (TMD) $[7,8]$ and energy dissipation schemes with viscous dampers. Because the deformation shape of high-rise building presents bending characteristics, compared with other energy dissipation schemes [9], a viscous damped outrigger can reduce the wind-induced acceleration with less viscous dampers while still yielding a high vibration reduction efficiency $[10,11]$.

Supertall building is featured by the huge construction cost and difficulty, so the most efficient location and a minimum number of outrigger trusses are key design issues. It is necessary to develop a simplified model to rapidly obtain 
the wind-induced acceleration of a supertall building with damped outriggers because time history analysis of the prototype model is time-consuming, which is not conducive for iterative design optimization. For instance, the design of a conventional wind-induced acceleration damped outrigger system requires repeated iteration analysis of the wind time history. Because of the large number of degrees of freedom (DOFs) of the prototype model structure and the nonlinear characteristics of the viscous dampers, the analysis takes 2-3 hours [12-14] for each calculation and 6-7 iterations for each optimization. Thus, basically 2-3 days will be needed to design the damped outrigger system in practice.

Currently, the simplified models used for analyzing the relationship between a damped cantilever system and the main structure proposed by Tan [15-20] are mostly based on a continuous cantilever beam, which simplifies the whole structure to a single-DOF cantilever beam and adds a vertical link aside from the cantilever beam to connect the outrigger beam. However, the current simplified cantilever beam model cannot simultaneously simplify the key factors, including the distance between the column and the core wall, the stiffness of the regular outrigger and the damped outrigger, and the deformation of the column, which are key to the hysteretic deformation difference between the core wall and the peripheral frame. There are three main sources of vertical difference deformation [13]. The first is that the outrigger rotates when the core wall bends, the second is that the outrigger itself bends under the load, and the third is that the peripheral mega-column deforms axially under the load. Apparently, this model cannot accurately simulate the role of the damped outrigger in controlling the structural wind-induced response. In addition, the mega-frame core wall structure is characterized by a secondary structure with a clear load path, and the simplification method should be specific. Therefore, a simplified plane model composed of both a shear wall and frame is needed in this particular study. The concept of the sliced model can be date back to Taranath [21] who simplified the structure and analyzed the optimal position of the belt truss in 1974. Lu et al. [22] developed a 2D simplified model composed of nonlinear beam-column elements and nonlinear spring elements for nonlinear seismic analysis of supertall buildings using the Shanghai Tower as a case study building. However, the simplified nonlinear parameters of the structural members are determined by experiment or simulation. Here, the simplified model is meant to reduce the extreme computational workload produced when using refined finite element (FE) models to do nonlinear analysis. Even though without nonlinearity, the simplified models are still needed in some circumstances where a large amount of reanalysis of supertall building is involved, such as the comparison of different structure schemes, the optimization of the structural members dimension, and the analysis of different input load and effect. In these circumstances, the parameters of the simplified model should have a strong and direct correspondence with the original model including the layout, the material, and the dimension of the structural members.
In this study, a simplified model and an optimization method of viscous damped outriggers for wind vibration control of mega-frame core wall structures are proposed. A simplified reduced-order model is developed and then validated against finite element results. Key structural properties affecting the dynamic behavior are identified by a wide parametric study. Combined with the simplified model, an optimization design method is proposed to minimize the cost of the damped outrigger system. Finally, an example is given to illustrate the accuracy and effectiveness of the simplified model and optimization design method.

\section{Theoretical Basis and Engineering Methodologies}

2.1. Mechanical Characteristics of the Mega-Frame Core Wall Structure. Recently, the mega-frame core wall structure has been widely used in high-rise buildings, including the Jin Mao Tower (1999, Shanghai, 88 stories, $421 \mathrm{~m}$ ), Taipei 101 (2004, Taipei, 101 stories, $508 \mathrm{~m}$ ), Shanghai Tower (2015, Shanghai, 128 stories, $632 \mathrm{~m}$ ), Guangzhou CTF Finance Center (2016, Guangzhou, 111 stories, $530 \mathrm{~m}$ ), and Lotte World Tower (2017, Seoul, 123 stories, $555 \mathrm{~m}$ ) [23].

As shown in Figure 1, the mega-frame core wall structure system is characterized by a secondary system, also known as the primary and secondary frame structures. The main frame is the mega-frame, which consists of mega-beams and megacolumns. The secondary frame is an ordinary frame, which consists of small cross-sectional members, and the ordinary frame is filled in the mega-frame. The geometric dimensions, area, and moment of inertia of the main frame are far greater than those of the secondary frame by an order of magnitude. Mega-columns are usually composed of elevator wells or large cross-sectional solid columns. Mega-beams are usually belt trusses set up on every few or more floors, and the height of beams generally accounts for one or more floors. The connections between the core wall and the periphery column consist of beams on ordinary floors and outriggers or beams on mechanical floors and refuge floors. An ordinary floor beam is usually connected to the column by a hinge connection. An outrigger is a type of mega-beam perpendicular to the belt truss.

The mechanical characteristics of the mega-frame core wall structure are as follows: the flexural rigidity of the outrigger truss that is used to connect the columns and core wall is very high, so the rotation angle of the core wall caused by the lateral load will cause tension or compression in the column. Because the force arm between the columns is large, it provides a tremendous antioverturning moment and greatly reduces the overturning moment carried by the core wall. The beam section of the nonoutrigger truss floor connecting the outer frame and the core wall is too small to restrain the column deformation, so its contribution to the lateral resisting system can be considered negligible. At the same time, because the lateral stiffness of the mega-frame is inversely proportional to the spacing between the strengthened layers, the lateral stiffness of the mega-frame is very small, and the core wall needs to bear the total horizontal shear force. 


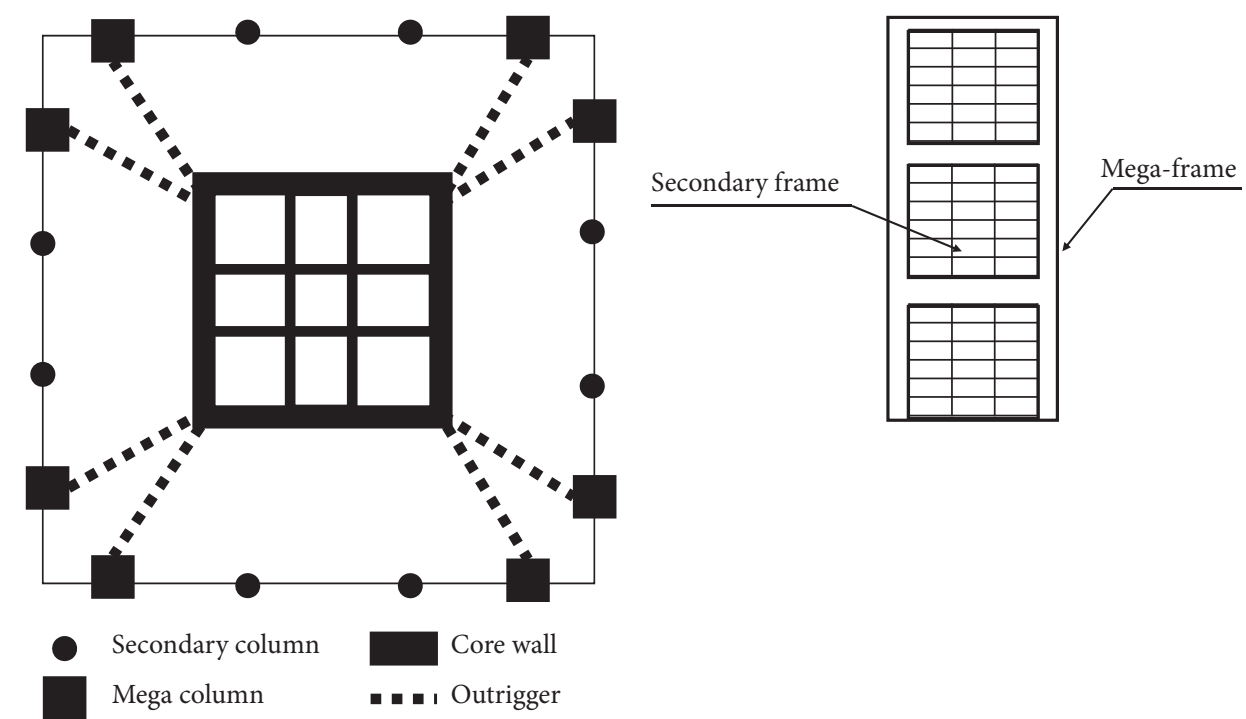

(a)

(b)

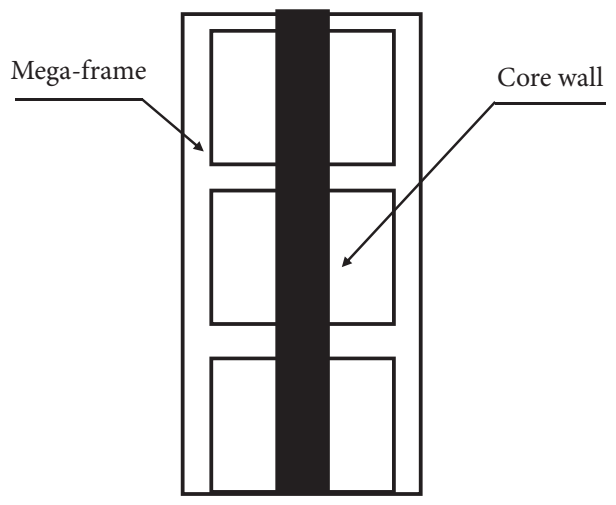

(c)

FIGURE 1: Schematic diagram of the mega-frame core wall structure system: (a) plan, (b) elevation, and (c) section.

2.2. Concept of the Viscous Damped Outriggers. The concept of using an outrigger motion amplifier was first proposed by Smith and Willford [9] of Arup, UK. As shown in Figure 2, there is a large vertical deformation difference between the outer frame column and the rigid outrigger truss extending from the core wall under lateral loads, and viscous dampers are installed vertically between them to achieve a better energy dissipation effect, which makes it important to consider both the columns and core wall simultaneously.

\subsection{Dynamic Analysis and Prediction Theory of the Wind} Vibration Acceleration. The dynamic analysis and prediction theory of wind vibration can be derived as follows [24]:

$$
m_{j} \ddot{x}_{j}+c_{j} \dot{x}_{j}+k_{j} x_{j}=F_{j}
$$

where the subscript $j$ represents the $\mathrm{jth}$ order mode, $m_{j}$ is the modal mass, $c_{j}$ is the modal damping coefficient, $k_{j}$ is the modal stiffness, and $F_{j}$ is the modal wind load time history. With the modal wind load spectrum $S_{F_{i}}(n)$, random vibration theory is used to solve formula (1) in the frequency domain, and the windinduced acceleration spectrum $S_{a_{j}}(n)$ can be obtained from

$$
S_{a_{j}}(n)=\left|H_{j}(n)\right|^{2} S_{F_{j}}(n),
$$

where $\left|H_{j}(n)\right|^{2}=(2 \pi n)^{4} /\left[1-\left(n / n_{j}\right)^{2}\right]^{2}+\left[2 \xi_{j} n / n_{j}\right]^{2}$ is the transfer function, $n$ is the circular frequency of the excitation frequency, $n_{j}$ is the circular frequency of the $j$ th mode, and $\xi_{j}$ is the damping ratio of the $j$ th mode.

Solve the equation to obtain the mean square value of the acceleration $\ddot{\sigma}_{a_{j}}^{2}$, as given in the following formula:

$$
\sigma_{a_{j}}^{2}=\int_{0}^{\infty} S_{a_{j}}(n) \mathrm{d} n=\int_{0}^{\infty}\left|H_{j}(n)\right|^{2} S_{F_{j}}(n) \mathrm{d} n .
$$

Since a wind-induced acceleration reaction is a narrowband process, the root mean square of modal acceleration can be approximated as shown in

$$
\ddot{\sigma}_{a_{j z}}=\varphi(z) \sqrt{S_{F_{j}}\left(n_{j}\right) \int_{0}^{\infty}\left|H_{j}(n)\right|^{2} \mathrm{~d} n} \cong \varphi(z) \sqrt{\frac{\pi n_{j} S_{F_{j}}\left(n_{j}\right)}{4 \xi_{j} m_{j}}},
$$




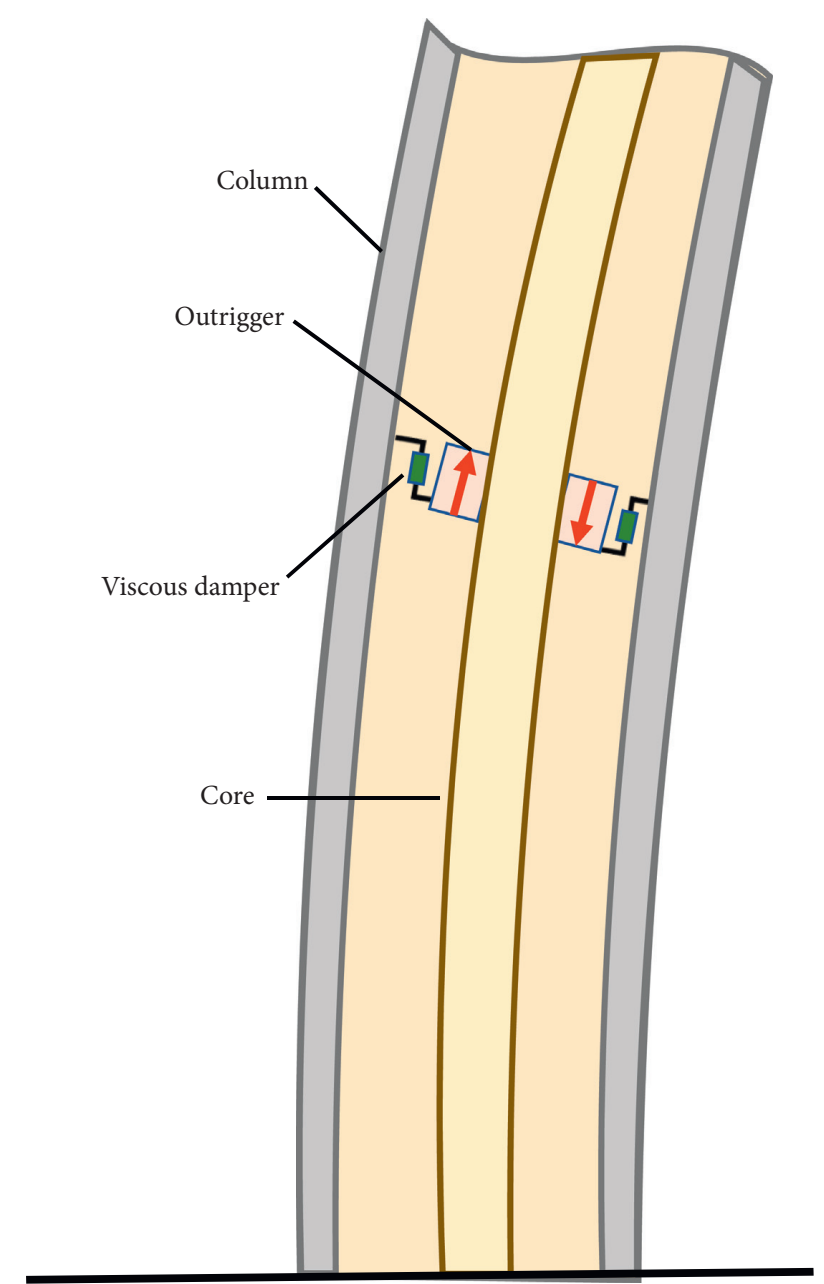

Figure 2: Damper connection mode of the damped outrigger.

where $\varphi(z)$ represents the normalized values of modal shape at height $z$.

Based on the parameters in formula (4), a simplified acceleration prediction model of a mega-frame core wall structure with a damped outrigger can accurately predict the acceleration when the simplified model has the same period and mode shape as the original model and the reduction factors of the load, modal mass, and damping coefficient are consistent with each other. To maintain the same period as the original structure, the stiffness should have the same reduction factor as the mass.

The stiffness ratio between the simplified model and the prototype model can be determined via static load-displacement analysis. The mode shape of the simplified model can be verified to be consistent with that of the prototype model by calculating the mode confidence criterion (MAC). Additionally, on the premise that the mode shape is consistent with that of the original model, the modal mass can have a reduction factor that is the same as the mass reduction factor.

2.4. Design Criteria for Wind Vibration Comfort. The acceleration limit of residences/apartments and offices/hotels under a 10-year return period wind load in the China Code of Technical Regulations for Concrete Structures of HighRise Buildings [25] is $0.15 \mathrm{~m} / \mathrm{s}^{2}$ and $0.25 \mathrm{~m} / \mathrm{s}^{2}$, respectively, as indicated in Table 1 . The case project selected in this study is a Chinese project and is used as a hotel. Thus, the structure needs to meet the limit of $0.25 \mathrm{~m} / \mathrm{s}^{2}$ at the vertex by adding viscous damped outriggers.

\section{Simplified Wind-Induced Human Comfort Prediction Model of a Mega-Frame Core Wall Structure}

3.1. Simplified Model Composition. It is reasonable to simplify the $3 \mathrm{D}$ model into $2 \mathrm{D}$ plan model for the coupled response is small. The structure is symmetric and the first torsion modal period is way shorter than the first two modal periods and the torsional modal participation factor is smaller than $1 \%$ in the first two modal. So, the square root of sum of squares (SRSS) method instead of complete quadratic combination (CQC) method can be applied in this case.

As shown in Figure 3, the simplified model proposed in this study simplifies the core wall of a supertall building as a shear wall element that can simulate the bending deformation of the core wall under lateral loads, and the megacolumn is simplified as a column element in the shear wall plane that can simulate the axial deformation of the megacolumn under lateral loads. The outrigger element is simplified as a beam that can simulate the self-deformation under a load. Only one slice of the prototype model is taken to simplify the model, and only the main components in the lateral resisting system are considered in the simplification process.

3.2. Simplification Method of the Structure Member. There are three components in the simplified model: wall, column, and beam.

The wall in the simplified model has the same geometry as the web wall and flange wall in the prototype, where the flange wall effective thickness equals 6 times the flange wall thickness plus the web wall thickness in accordance with Chinese code [26], as shown in formula (5). If there is a narrow opening in the middle of the web wall, then it is believed that the wall bending stiffness weakening is relatively small and that the wall still agrees with the plan-section assumption, so the web wall can be simplified to a piece of integrated wall with a length of $L_{W}$, as shown in Figure 4. When the opening is relatively wide, the opening should be included in the simplified model as its original dimensions:

$$
L_{F}=T_{W}+6 T_{F},
$$

where $L_{F}$ is the length of the flange wall, $T_{W}$ is the thickness of the web wall, and $T_{F}$ is the thickness of the flange wall.

The column in the simplified model should have the same section as the prototype, as shown by $b$ and $h$ in Figure 4. For the unidirectional reaction, the overturning moment in the wall plane provided by the column is proportional to the vertical distance between the column and wall. Thus, the column and wall are simplified into a plane 
TABLE 1: The limit of vertex acceleration [25].

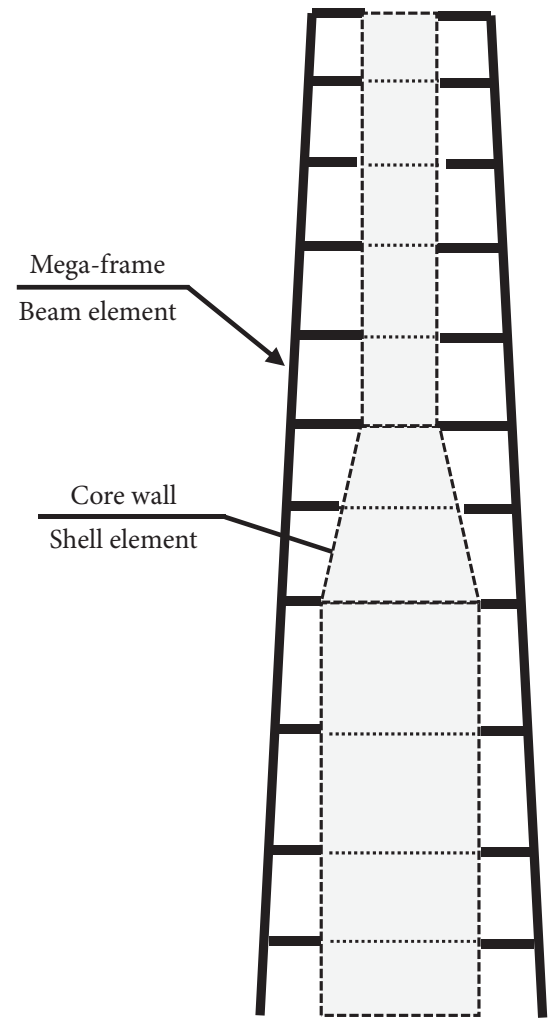

Figure 3: Composition of the acceleration prediction simplified model.

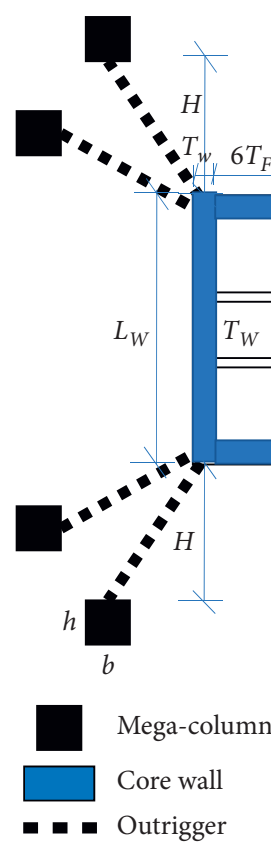

Figure 4: Simplified method for the wall and column elements. 
model in which the columns are pushed horizontally into the web wall plane. Thus, the distance in the vertical direction is the same as the prototype and is denoted by $H$ in Figure 4 . In this way, the $3 \mathrm{D}$ prototype model is condensed to the "sliced" model. Although there are four columns on the lefthand side on the plan view in the prototype model, only the two columns that are nearer to the plane who can provide most of the resistance in that direction are taken into consideration. Firstly, these two columns have larger $H$, which means they can provide large overturning moment. Secondly, the beams out of plane which connect the core and the other two columns can only transfer little bending moment through torsion displacement.

As shown in Figure 5, the mega-beam between the core and column in the prototype can be divided into 3 categories: one is the rigid outrigger, one is the damped outrigger, and one is no outrigger. The simplified methods differ correspondingly. The rigid and damped outrigger will be simplified as normal beams with the same stiffness. The region without the outrigger and the gap between the column and damped outrigger will be simplified as a rigid bar with both ends released to simulate the horizontal restriction provided by the slab.

The outrigger truss is simplified as a beam for these 3 reasons. First, the simplified beam was intended to represent both the outrigger truss and the regular floor beam, that is, the total coordination effect between the column and core wall. Because the truss is much larger than the regular floor beams, simplifying the truss can effectively simulate the structural behavior in the mega-frame core wall structure. Second, the simplified model is developed to be as simple as possible, and the beam element is easier for programming and studying than the truss. Third, the beam element has a clear physical meaning that corresponds to the total coordination effect rather than just a part of it, which makes it easy to obtain a simplified model by adjusting the beam size. If this simplified method is used in a normal frame core wall structure without an outrigger truss, then this simplified beam element can still be used to represent the connection between the column and wall.

The two nodes connected to the core wall are restricted and fixed. Then, the load on the other side is set to obtain the deformation via finite element method (FEM) analysis, as shown in Figure 6.

Based on elastic theory, the deformation of the cantilever beam is $\Delta=\left(P l^{3} / 3 E I\right)\left(1+2.78\left(h^{2} / l^{2}\right)-0.84\left(h^{3} / l^{3}\right)\right)$, where $P$ is the concentration load at one end, $l$ is the length of the members, $E$ is the elastic modulus, $I$ is the bending stiffness, and $h$ is the beam height. When the length to height ratio is greater than 5 , the equation can be simplified into the Euler beam equation $\Delta=P l^{3} / 3 E I$ [27]. Thus, the stiffness can be back-calculated according to the elastic equation, and the beam size and stiffness can be further adjusted according to the dynamic characteristic difference between the simplified and prototype models.

3.3. Simulation of the Damper Connection. In the prototype, the outrigger is connected to the core wall directly and is connected to the column with dampers, as shown in Figure 7. The outrigger is separated from the floor, so the deformation of the outrigger is unrelated to the floor slab.

Figure 8 shows the damper simulation in the simplified model. Beam 1 is used to model the outrigger. Beam 2, the rigid bar, is used to model the floor slab horizontal restriction on the mega-column. The rotational displacement of both ends is released, and the vertical displacement of one end is released. In this manner, the horizontal without a vertical restriction can be modeled by Beam 2 .

\subsection{Applicability and Robustness of the Simplified Model.} Based on the mechanical characteristics of mega-frame core wall structures, a sensitivity analysis of key parameters in the simplified model is performed using the commercial software "SAP2000" and the open source software "python." As an example, a simplified model of a supertall building whose dimensions are shown in Section 5 is used. The mass remains unchanged while changing the stiffness of the members to analyze the influence of the member size simulation accuracy on the accuracy of the prediction result. The applicability and robustness of the simplified model are demonstrated, and the key factors affecting the prediction results are identified.

3.4.1. Influence of the Column Section Axial Stiffness Coefficient on the Structure Period. Because the force arm between the columns is large, it provides a tremendous antioverturning moment and greatly reduces the overturning moment borne by the core wall. It can be inferred that the axial stiffness and angle of the column are key to the structure stiffness, which is embodied by the structure period. As shown in Figure 9, when the axial stiffness is reduced to half, the period increases by $1.2 \mathrm{~s}$. Although the structure stiffness is sensitive to the column axial stiffness, the cross-sectional area and angle can be easily obtained and can be expressed in exactly the same way as the prototype.

\subsubsection{Influence of the Column Section Shear Stiffness on the} Structure Period. Since the column has a large slenderness ratio, the column can provide only the shearing capacity by bending deformation, and as shown in Figure 10, changing the section shear stiffness from half to double has almost no influence on the structure period; that is, the simulation of the height-width ratio of the column section is not the key factor affecting the accuracy of the prediction results of the simplified model. Thus, it can be inferred that although the cross section of columns in mega-frame core wall structure is often irregular, a simple square or circle cross section can be used to represent the prototype.

\subsubsection{Influence of the Column Section Bending Stiffness on the} Structure Period. Since the slenderness ratio of the column is relatively large and the section is much smaller than the core wall, which means that the bending stiffness provided by the column is much less than that provided by the core wall, the bending stiffness coefficient of the column has a 


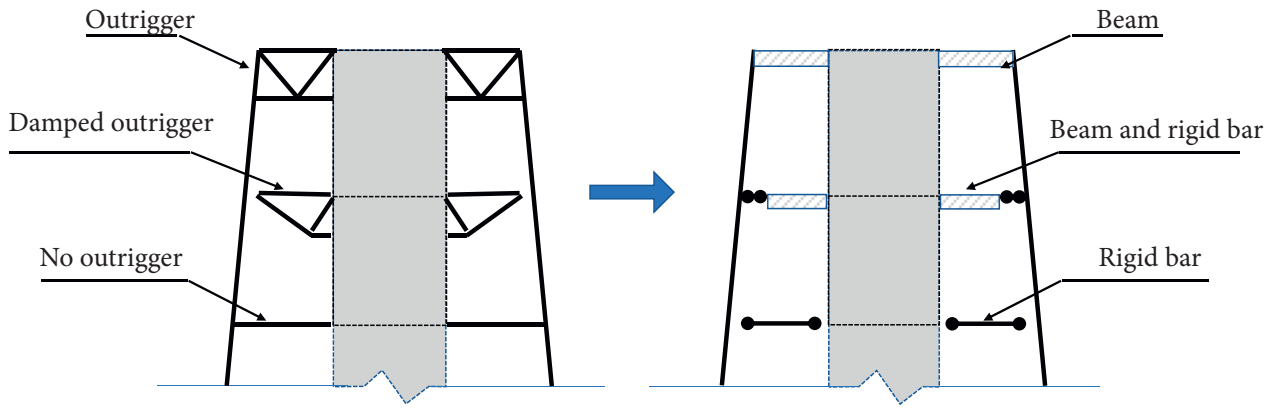

FIGURE 5: Simplified method of the mega-frame beam element.

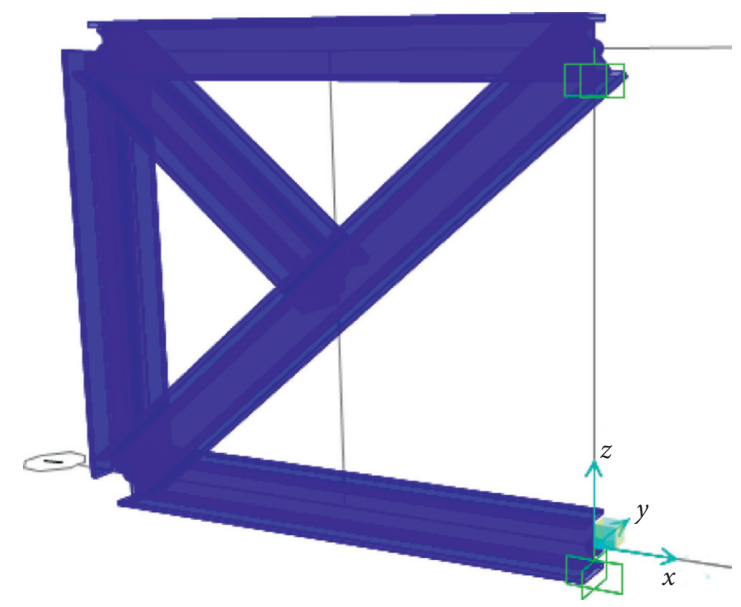

(a)

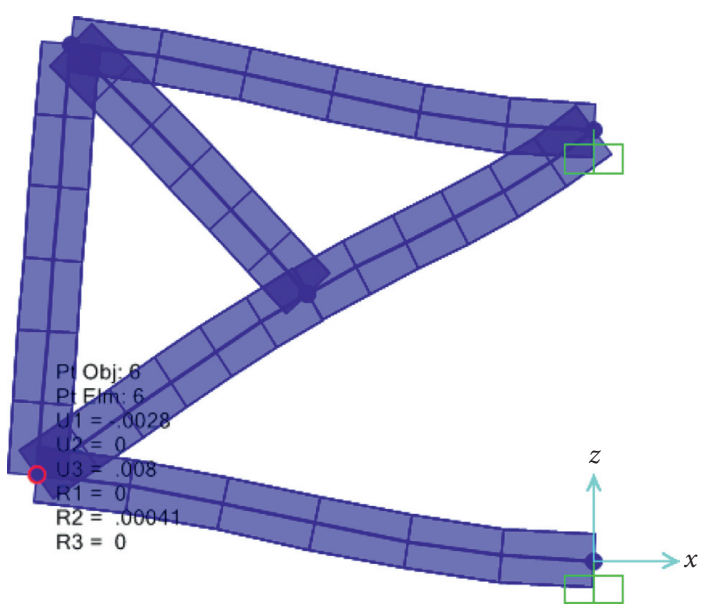

(b)

FIGURE 6: The outrigger FEM model: (a) before deformation; (b) after deformation.

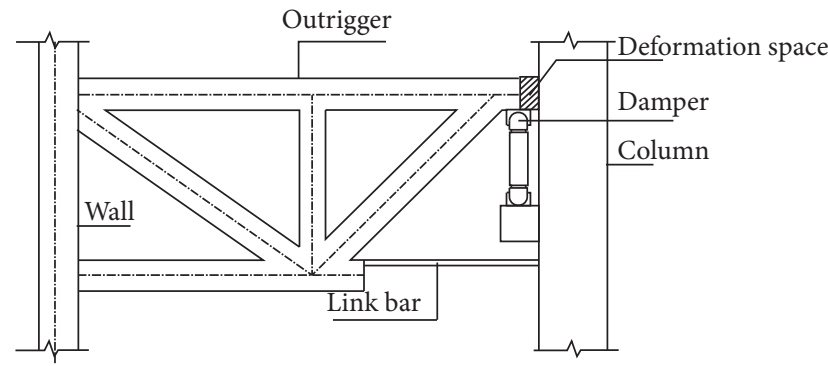

Figure 7: Damped outrigger layout.

small influence on the structure. As shown in Figure 11, when the column stiffness is doubled, the period decreases by $0.2 \mathrm{~s}$, and even when the stiffness is reduced to $1 / 10$, the period increases by no more than $0.5 \mathrm{~s}$, which shows that the bending stiffness has almost no influence on the structure stiffness; that is, the simulation of the height-width ratio of the column section is not the key factor affecting the accuracy of the prediction results of the simplified model. Thus, it can be inferred that although the cross section of columns in mega-frame core wall structure is often irregular, a simple square or circle cross section can be used to represent the prototype.

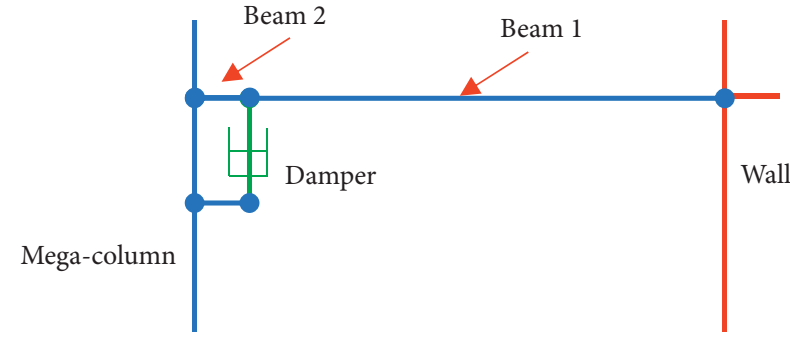

FIGURE 8: Damper in the simplified model.

3.4.4. Influence of the Beam Section Bending Stiffness on the Structure Period. It can be inferred that the beam section has a greater impact because the axial force in the column is transferred by the beam as a shear force. Figure 12 shows that when the beam is too weak to coordinate the core wall and periphery frame, the period is considerably elongated, but when the beam line stiffness is much greater than that of the column, the period cannot increase along with it. From Figure 13, it can be inferred that in the scope of the normal size of the mega-frame, the stiffness of the outrigger is much greater than that of the column because when the stiffness is double or half, the period only changes by approximately $0.2 \mathrm{~s}$. This result is in accordance with the fact that the 


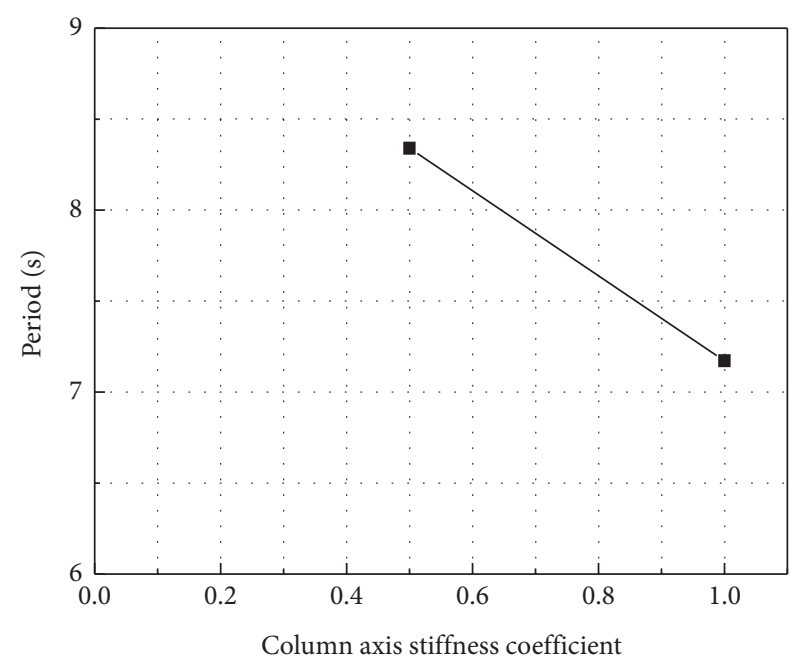

FIGURE 9: Influence of the column section axial stiffness on the period.

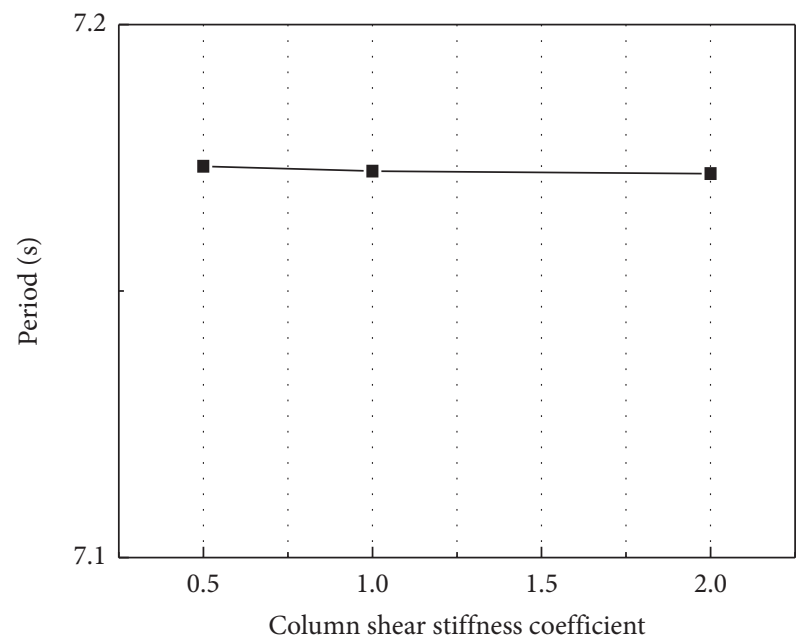

FIGURE 10: Influence of the column section shear stiffness coefficient on the period.

outrigger normally occupies one or two stories, which equals 5 to 10 meters, and the column section usually ranges from 0.8 to a maximum of 5 meters. Thus, in the regular size range, the beam section is large enough that the accuracy of its simulation has little effect on the results.

3.4.5. Influence of Ignoring the Normal Floor Beam on the Structure Period. Because the hinged connection between the floor beams and the columns cannot restrain the deformation of the mega-columns, even when the beams and columns are rigidly connected, the coordinated effect of the beams on ordinary floors can be neglected due to its small cross-sectional area. Based on the previous argument, it can be observed that even if the introduction of beams can improve the coordination effect between the core and column or can slightly improve the flexural and shear stiffness

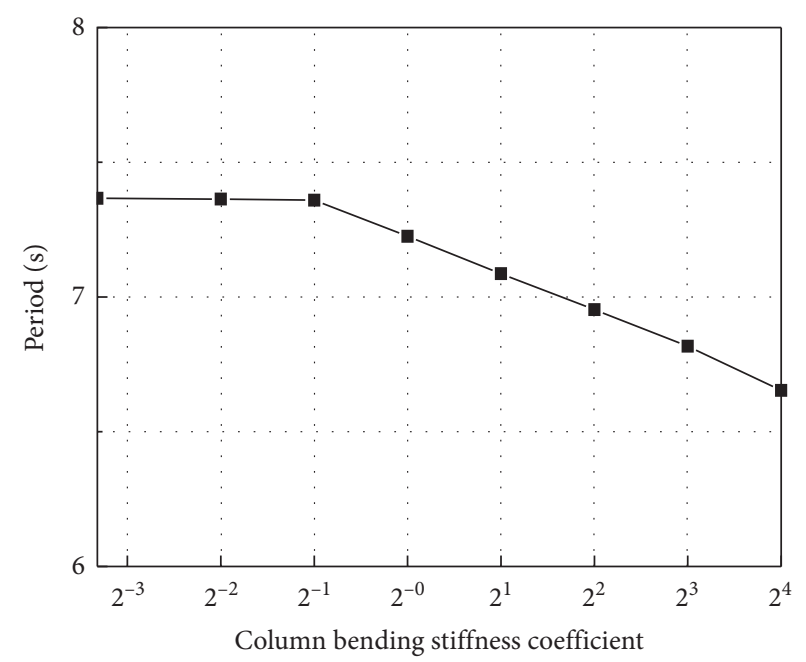

FIGURE 11: Influence of the column section bending stiffness coefficient on the period.

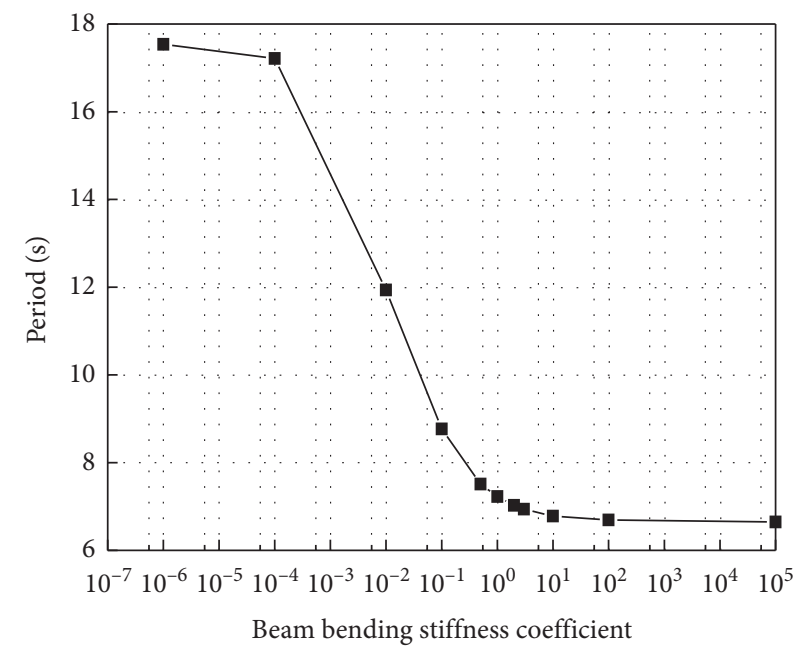

FIgURE 12: Influence of the beam section bending stiffness $\left(10^{-7} \sim 10^{5}\right)$ on the period.

of columns, the impact of structural stiffness and period is not significant, which is indicated in Table 2.

3.4.6. Influence of the Core Wall Bending Stiffness on the Structure Period. Because the supertall is high, the wall can be seen as a cantilever beam member, and the bending stiffness will greatly impact the structure stiffness. The bending stiffness is mainly decided by the flange wall, while the web wall mainly transfers the shear force, which resembles $\mathrm{H}$-shaped beams. This point can be verified from Table 3, which shows that the period significantly drops from $7.3 \mathrm{~s}$ to $6.3 \mathrm{~s}$ when adding the flange wall to the simplified model without the flange wall.

3.4.7. Influence of the Wall Bending Stiffness on the Mode Shape. To compare the correlation of the first-order modes 


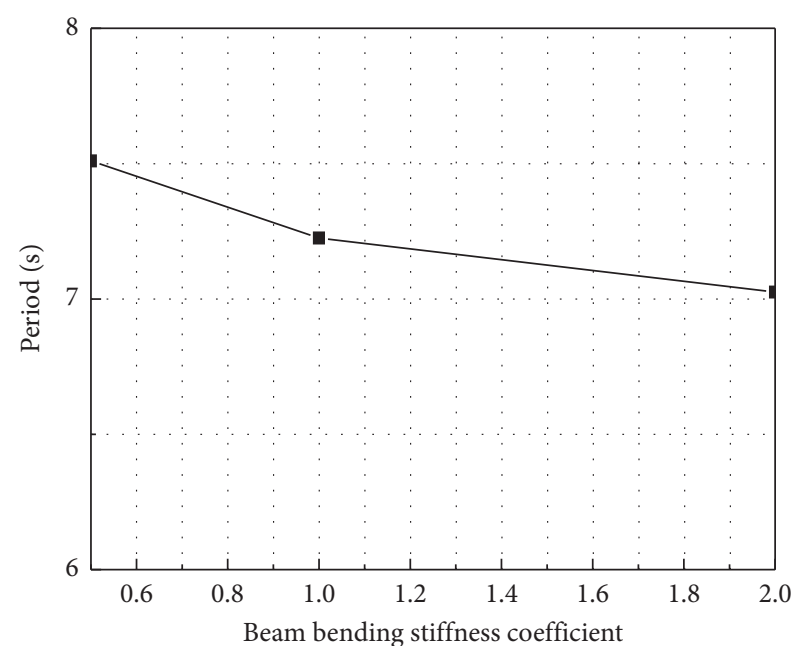

FIGURE 13: Influence of the beam section bending stiffness (0.6-2) on the period.

TABLE 2: Influence of ignoring the normal floor beam on the structure period.

\begin{tabular}{lcc}
\hline & $\begin{array}{c}\text { Without the normal } \\
\text { floor beam }\end{array}$ & $\begin{array}{c}\text { With the normal floor } \\
\text { beam 1 }\end{array}$ \\
\hline $\begin{array}{l}\text { Structural } \\
\text { period (s) }\end{array}$ & 7.3 & 7.3 \\
\hline
\end{tabular}

TABLE 3: Influence of the core wall bending stiffness on the structure period.

\begin{tabular}{lcc}
\hline & $\begin{array}{c}\text { Without the } \\
\text { flange wall }\end{array}$ & $\begin{array}{c}\text { With the } \\
\text { flange wall }\end{array}$ \\
\hline Structural period (s) & 7.3 & 6.3 \\
\hline
\end{tabular}

between the simplified model and prototype, the concept of the MAC is introduced as follows:

$$
\operatorname{MAC}_{i j}=\frac{\left|\phi_{i}^{T} \phi_{j}\right|^{2}}{\phi_{i}^{T} \phi_{i} \phi_{j}^{T} \phi_{j}}
$$

where $\phi_{i}, \phi_{j}$ is the mode vector, $T$ represents vector transposition, and the subscripts $i$ and $j$ represent the $i$ th and $j$ th modes, respectively. The closer the MAC is to 1 , the more correlated the two modes are.

The flange wall stiffness coefficient is changed, and the data from the two models are extracted. The normalized first-order mode shapes are drawn in Figure 14, and the MAC values are listed in Table 4.

The results show that the MAC values are greater than 0.999 when the flexural stiffness of the wall doubles or decreases by half. That is, the mode distribution is not sensitive to the absolute size of the simplified model wall members and the relative stiffness of the wall-column members. It is easy for the first mode shapes of the simplified

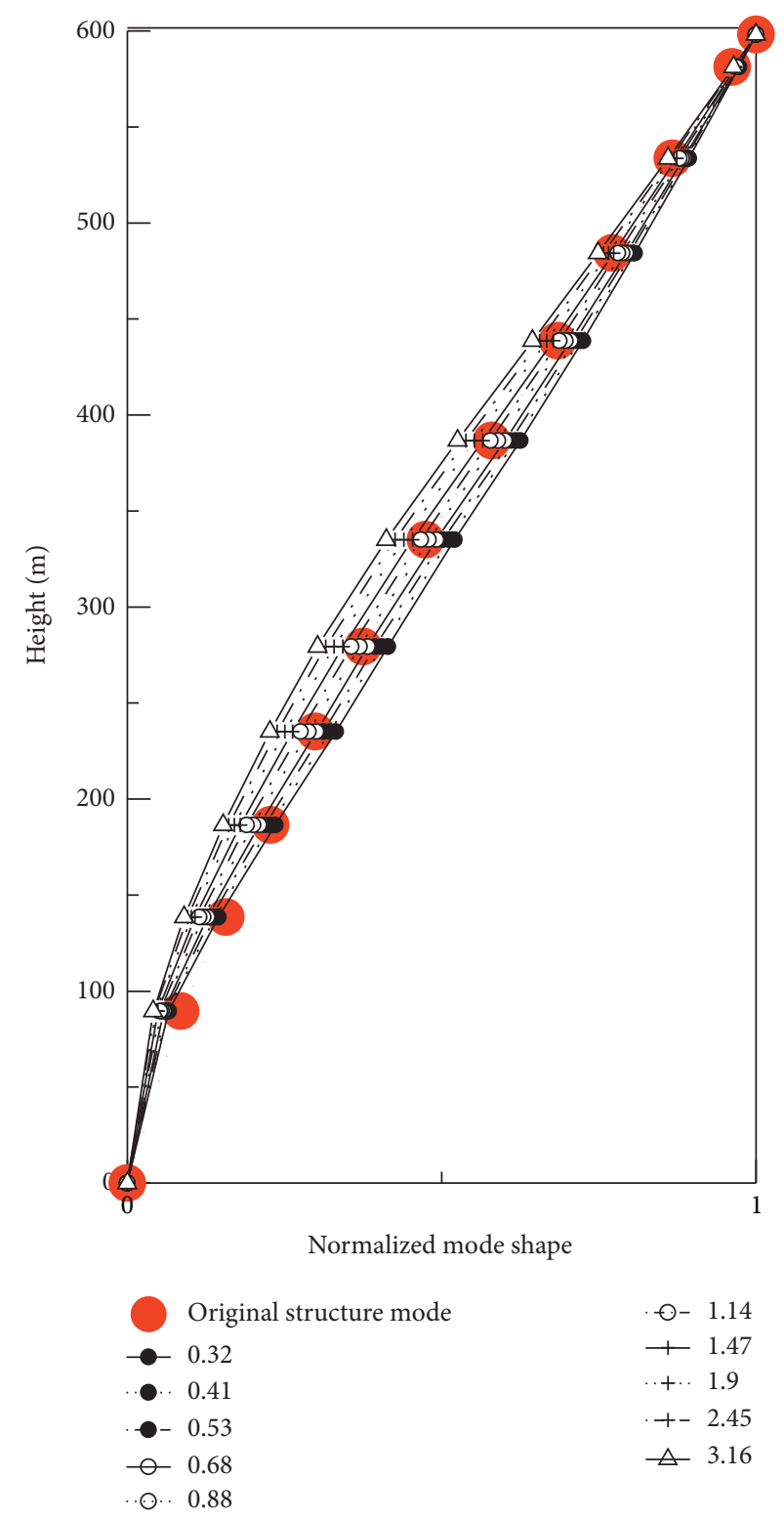

FIGURE 14: Sensitivity of the first-order mode shape to the flange wall stiffness of the simplified model.

TABLE 4: Structural period and MAC value corresponding to the flange wall stiffness coefficients.

\begin{tabular}{lccc}
\hline No. & Flange wall stiffness coefficients & Period $(\mathrm{s})$ & MAC \\
\hline 1 & 0.32 & 8.8 & 0.9989 \\
2 & 0.41 & 8.68 & 0.9991 \\
3 & 0.53 & 8.55 & 0.9993 \\
4 & 0.68 & 8.39 & 0.9994 \\
5 & 0.88 & 8.2 & 0.9992 \\
6 & 1.14 & 8 & 0.9988 \\
7 & 1.47 & 7.77 & 0.9981 \\
8 & 1.9 & 7.52 & 0.9971 \\
9 & 2.45 & 7.25 & 0.9959 \\
10 & 3.16 & 6.95 & 0.9944 \\
\hline
\end{tabular}


model to resemble that of the prototype, which ensures the accuracy of the predicted results of the simplified model. It can be observed from the following figure that when the stiffness correction factor of the flange wall is close to 1 , the shape of the simplified model is closest to that of the prototype model, which verifies the feasibility of the flange wall effective width methodology.

Based on the research above, the following conclusions can be made:

(1) Without considering the secondary structure, the period of the prototype structure can be well simulated by a simplified plane structure consisting of mega-frames and shear walls

(2) The simplified model period is insensitive to the beam section size and the flexural and shear stiffness of the wall and column

(3) The axial stiffness and angle of the column and the bending stiffness of the wall in the simplified model are the key factors to ensure prediction accuracy

\section{Optimal Design of the Damped Outriggers on Human Comfort Performance}

4.1. Definition of the Optimization Problem. The optimization objective is to obtain the minimum cost of a viscous damped outrigger system used in the main structure for wind load human comfort control.

The optimization variables of the viscous damped outrigger system include the floor arrangement of the viscous damped outrigger, the damper number in one location, and the damping coefficient of the viscous damper. The greater the damper deformation is, the more obvious the energy dissipation effect of the viscous dampers, which means that the optimal placement of the viscous dampers can improve the utilization efficiency of the viscous dampers. The cost of the viscous damper is related to the damping exponent, stroke, and output, in which the stroke of the damper is related to the position of the damper, and the output of the damper is related to the stroke and damping coefficient as well as the damping exponent. Because the strokes are not considerably different from each other within different floors, as demonstrated from the case study, and the damping exponent used in wind engineering should be small enough to yield a force when the velocity is relatively small under minor wind loading, the damping coefficient of the damper is taken as a simplified cost index. Additionally, the damping exponent is taken as a constant value of 0.3 due to the damping exponent of the dampers used in the construction industry generally being greater than $0.3-0.5$, because when the exponent is quite small, further reduction of the exponent requires major processing technique improvement, but the energy consumption efficiency is only increased by less than $10 \%$ [28]. In this study, it is assumed that the damped outrigger truss has the same section as the regular outrigger truss. Thus, the cost of the damper is proportional to the damping coefficient.
The optimization problem has the following characteristics and preconditions according to the major engineering practices:

(1) The driven constraint is the vertex acceleration, which meets the Chinese Code requirements, and is $a \leq 25 \mathrm{~cm} / \mathrm{s}^{2}$.

(2) The damping coefficient is less than $700 \mathrm{kN} /(\mathrm{mm} / \mathrm{s})^{0.3}$ according to the common available product parameter. The damping exponent is 0.3 .

(3) Damping outriggers need to be installed in the equipment floors without rigid outriggers, since megastructures need rigid outriggers to strengthen the lateral stiffness. Because the outriggers occupy the floor space and the dampers need overhauling, and considering the architectural space availability, the outriggers are usually located in the mechanical floors and refuge floors only [29]. One or two dampers can be connected at the end of each outrigger. That is, the number of viscous dampers that can be connected at each location is 0,1 , or 2 , where 0 represents no viscous damped outrigger. When the viscous damped outrigger is added, the size of the outrigger is the same as that of the rigid outrigger.

(4) According to the principle of product normalization, all dampers are assumed to be of the same type; that is, all dampers have the same damping coefficient, exponent, and stroke.

The mathematical model of the optimization problem can be expressed as given in

$$
\begin{aligned}
& \text { Find } \quad x \in R^{2} \\
& \text { Min } \quad f(x)=\sum C_{i} \\
& \text { s.t. } \quad a \leq 25 \mathrm{~cm} / \mathrm{s}^{2} \\
& C_{i}<700 \mathrm{kN} /(\mathrm{mm} / \mathrm{s})^{0.3} \\
& C_{i}=C_{j} \\
& \begin{array}{l}
\alpha=0.3 \\
n \in(0,1,2) \\
n=0 \quad \text { when there is already a rigid outrigger }
\end{array}
\end{aligned}
$$

where $x=(n, C)$ is a two-dimensional optimization variable and $n$ is the number of dampers arranged at the available position. If $n$ is 0 , it means no damper is arranged at a certain position. $C$ is the damping coefficient. The function $f(x)$ represents the objective function, which is the cost of the viscous dampers required by the viscous damped outrigger; $C_{i}$ and $C_{j}$ represent the damping coefficients of dampers arranged on the $i$ th- and $j$ th-numbered floors; and the damping exponent $\alpha$ is constant.

\subsection{Characteristic of the Controlling Effect of the Damped} Outrigger. This problem has the following characteristics, which can be verified through an idealized model whose damper number and damping coefficient can vary over a wide range as shown in Figure 15: 


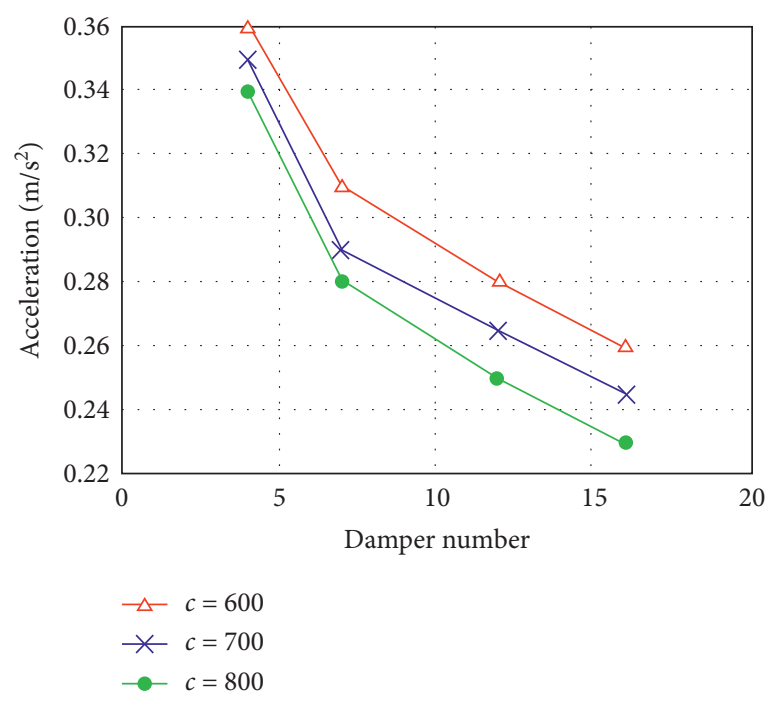

(a)

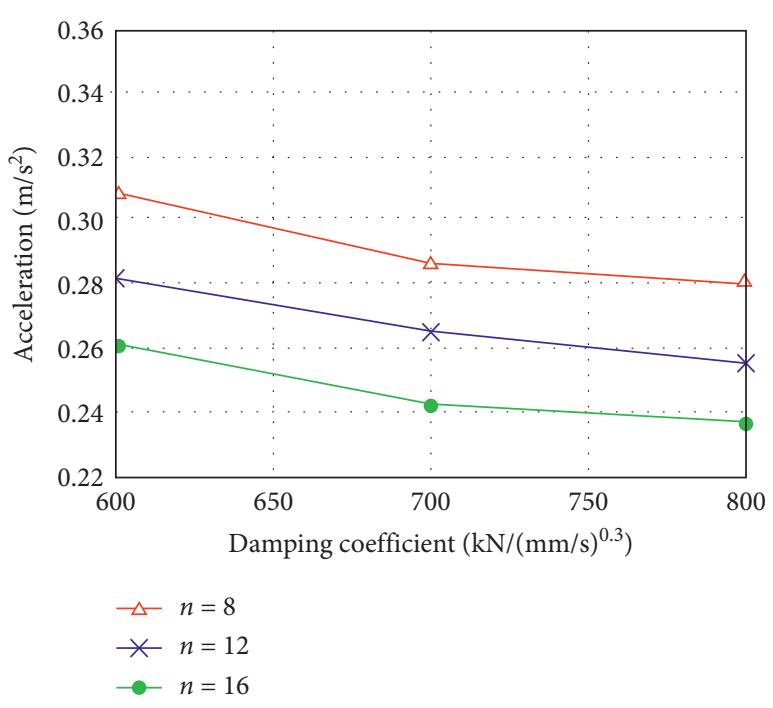

(b)

Figure 15: Characteristic of the controlling effect of the damped outrigger. (a) Damper number-peak acceleration curve. (b) Damping coefficient-peak acceleration curve.

(1) With the same damping coefficient, the peak acceleration of the structural vertex decreases with increasing damper number, as shown in Figure 15(a). Therefore, when the damper damping coefficient is determined, there must be an optimal number of dampers to render the peak acceleration of the structure vertex close to the limit.

(2) When the number of dampers is constant, the acceleration of the structural vertex decreases approximately linearly with an increase in the damper damping coefficient, as shown in Figure 15(b). Therefore, when the number of dampers is determined, there must be a minimum value of the damping coefficient such that the peak acceleration of the structure vertex meets the limit value.

Because the damping system is an additional system that has little influence on the dynamic characteristic of the original structure, when the excitation is small, the damping effect is almost linearly proportional to the damping coefficient. Thus, the optimization method should utilize the most efficient position first and then add new dampers according to the efficiency sequence.

\subsection{Optimization Method of the Damped Outrigger for Controlling the Wind-Induced Acceleration}

4.3.1. Optimal Design Procedure. The optimal design procedure of a viscous damped outrigger system with constraint conditions of wind-induced human comfort is divided into four stages:

(1) Establish a simplified model and carry out static load analysis to obtain the reduction factor of the stiffness, which is also the reduction factor for the wind load, damping coefficient, and mass.
(2) Iterate the location and number of viscous dampers until the acceleration is less than the code limit; the design process is detailed in 4.3.2.

(3) Reduce the damping coefficient iteratively until the acceleration is close to the code limit. The design process is detailed in 4.3.3.

The flowchart of the optimal design is shown in Figure 16.

4.3.2. Optimization of the Number and Location via the Sensitivity Vector Algorithm (SVA). $S_{0}$ is assumed to be the state of the building without damped outriggers, and $\mathbf{a}_{0}$ is the single line matrix that consists of the acceleration of the target stories that correspond to state $S_{0}$. $\mathbf{a}_{\mathbf{0}}$ can be the accelerations of each story, or if the building is a complex building consisting of different functions, then $\mathbf{a}_{0}$ can be the acceleration of the top floor of each function area. In the same manner, $S_{i}$ stands for the state of the building with damped outriggers set in the $i^{\text {th }}$ zone, and $\mathbf{a}_{\mathbf{i}}$ corresponds to the state $S_{i}$. When the outriggers are more than 2, the location can be marked as the subscript. For example, $S_{2,6}$ means the outriggers are set in zone 2 and zone 6 , and $\mathbf{a}_{2,6}$ represents the accelerations of the building corresponding to state $S_{2,6}$. Then, a dimensionless vector called the sensitivity vector can be defined as follows:

$$
\mathbf{r}_{\mathbf{i}}=\mathbf{a}_{\mathbf{i}} / \mathbf{a}_{0}
$$

where ./ represents the division of corresponding items.

The sensitivity vector $\mathbf{r}_{\mathbf{i}}$ reflects the contribution of the damped outrigger set in zone $i$ to the acceleration of the target story. Since the damped outriggers do not induce stiffness and the additional damping ratio is usually less than $5 \%$, the contribution of each damped outrigger to the entire structure can be considered independent each other. This 


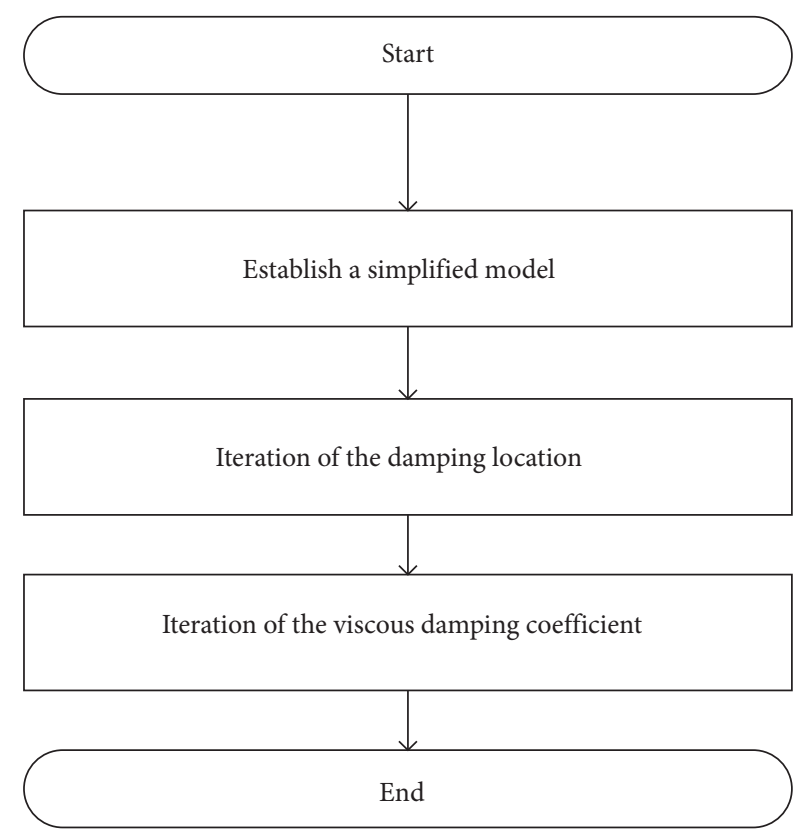

FIGURE 16: Flowchart of the optimal design of the damped outrigger system design.

result can also be seen in Figure 15. Therefore, the contribution of the combined outrigger set in different zones can be expressed as follows:

$$
\mathbf{r}_{\mathbf{i}, \mathbf{j}, \mathbf{k}}=\mathbf{r}_{\mathbf{i}} \cdot * \mathbf{r}_{\mathbf{j}} \cdot * \mathbf{r}_{\mathbf{k}},
$$

where ${ }^{*}$ indicates multiplication of the corresponding items.

Then, the acceleration of the building with an arbitrary combination of the outrigger $\mathbf{a}_{\mathbf{i}, \mathbf{j}, \mathbf{k}}$ can be easily obtained as long as the single sensitivity vectors $\mathbf{r}_{\mathbf{i}}, \mathbf{r}_{\mathbf{j}}$, and $\mathbf{r}_{\mathbf{k}}$ are calculated. This acceleration can be expressed as follows:

$$
\mathbf{a}_{\mathbf{i}, \mathbf{j}, \mathbf{k}}=\mathbf{r}_{\mathbf{i}, \mathbf{j}, \mathbf{k}} \cdot * \mathbf{a}_{0},
$$

where $\cdot^{*}$ indicates multiplication of the corresponding items.

Finally, to choose the favorable arrangement of the building with the acceleration constraint, the sensitivity vector algorithm method is listed as follows:

(1) Calculate the acceleration of the structure without outriggers and with a single outrigger set in each zone

(2) Use formula (7) to obtain the sensitivity of each outrigger

(3) Use formulas (8) and (9) to obtain the acceleration of the arbitrary combination of outriggers

(4) Choosing from all the schemes, the best scheme with a certain number of outriggers can then be obtained

(5) Checking the constraints and the acceleration of the scheme obtained in 4 , the scheme with the least number of damped outriggers will be the final choice in this stage

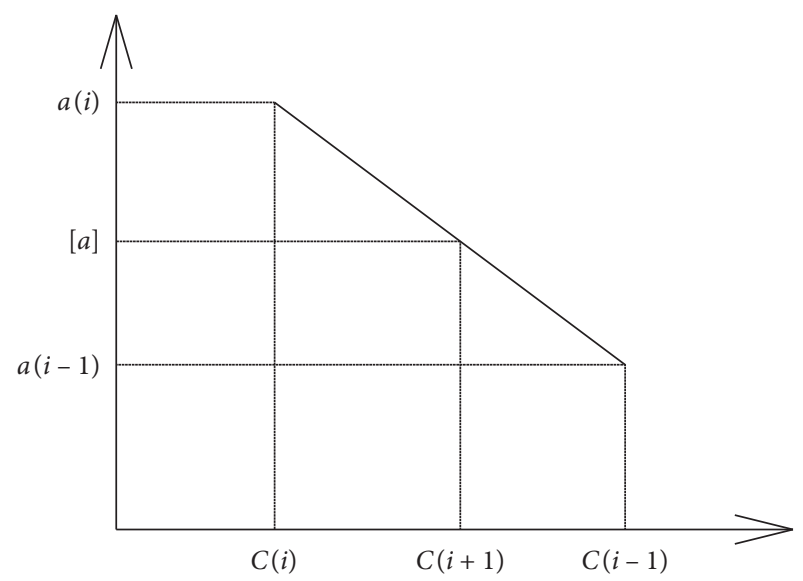

FIGURE 17: Damping coefficient-acceleration linear interpolation.

4.3.3. Optimization of the Damping Coefficient. When the vertex acceleration is less than the code limit, the number of dampers remains unchanged, and the viscous damping coefficient is reduced from the fixed maximum to a suitable value to meet the comfort limit. Because the response of the structure is approximately linear with the damping coefficient, the damping coefficient of the next iteration can be determined via a linear interpolation method, as shown in Figure 17. The method is that when the damping coefficients of the structure with a viscous damper are $C(i)$ and $C(i-1)$, the corresponding accelerations of the structure vertex are $a(i)$ and $a(i-1)$. At the same time, the acceleration limit of the structure vertex is $[a]$, and the damping coefficient can be re-estimated using formula (10). The obtained damping coefficient is updated in the simplified model, and the peak acceleration of the structure is recalculated. When the difference between $a(i+1)$ and $[a]$ is less than $1 \%$, i.e., $0.25 \mathrm{~m} /$ $\mathrm{s}^{2}$, the optimal damping coefficient of the damper is chosen to be $C(i+1)$, which stops the iteration.

The damping coefficient can be optimized according to the following equations:

(1) Determine whether it is the first time to reduce the damping coefficient, and if so, execute step (2); otherwise, execute step (3).

(2) Update the damping coefficient according to formula (10) and reanalyze the structure. Then, jump to step (4):

$$
C(i+1)=C(i) \cdot \frac{a(i)}{[a]} .
$$

(3) Update the damping coefficient according to formula (11) and reanalyze the structure. Then, jump to step (4):

$$
C(i+1)=C(i)+\frac{a(i)-[a]}{a(i)-a(i-1)} \cdot(C(i-1)-C(i)) .
$$




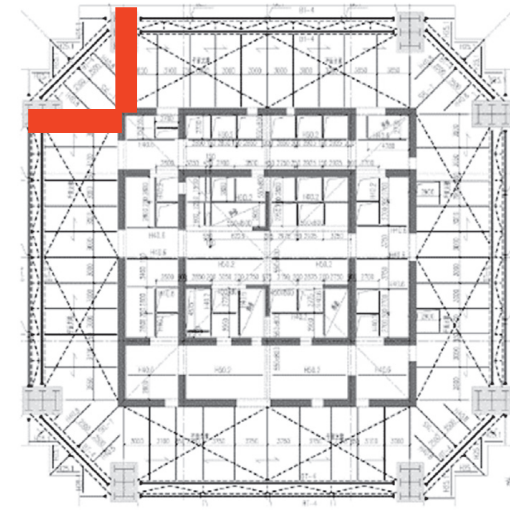

Outrigger

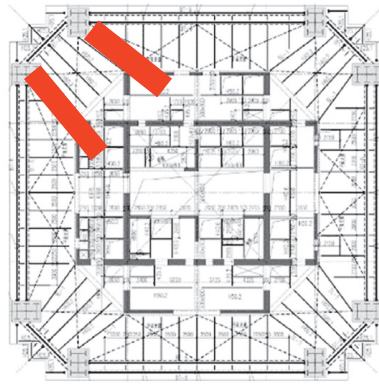

Outrigger

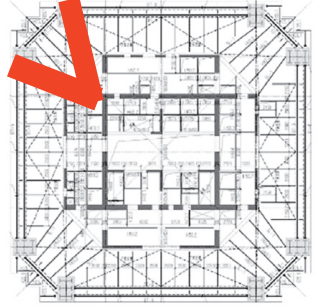

Outrigger

FIgURE 18: Lateral load-resisting system.

(4) Determine whether convergence conditions (12) and (13) are satisfied at the same time. If so, stop the iteration; if not, return to the first step:

$$
\begin{gathered}
a(i+1)<0.25 \mathrm{~m} / \mathrm{s}^{2}, \\
a(i+1)-[a] \leq 0.0025 \mathrm{~m} / \mathrm{s}^{2} .
\end{gathered}
$$

Here, $a(i)$ is the peak acceleration of the ith iteration, $C(i)$ is the damping coefficient of the ith iteration, and $[a]$ is the code limit of the peak acceleration under the 10-year return period wind load.

\section{Case Study}

5.1. Project Overview. A megatall building is presented as a case study; the structure has 138 floors above ground and is $598 \mathrm{~m}$ in height. The structure is a complex of commercial buildings in the lower zones, offices in middle zones, and hotels in higher zones. The lateral resisting system is composed of a shear wall core wall, mega-columns, belt trusses, and rigid outriggers, as shown in Figure 18. The structure is divided into 12 zones vertically. Each zone has a belt truss, and there are five rigid outriggers in zones 5, 7, 8, 9 , and 11 , as indicated in Table 5. Table 6 presents the outrigger size of the prototype. Within the architecture boundary limits, a viscous damped outrigger can only be arranged in six locations without a rigid outrigger, i.e., zones $1,2,3,4,6$, and 10 , with a maximum of eight damped outriggers in each zone. One or two viscous dampers can be arranged at the end of each damp outrigger. Figure 19 shows the layout of a typical floor. Table 7 reports the size of the structural shear wall. Table 8 presents the size of the structure column. In this case, the two directions of the structure are basically the same, so only one direction is considered in the following optimization process.

The return period is 10 years, and the wind pressure is $0.30 \mathrm{kN} / \mathrm{m}^{2}$, which consists of the wind environment parameters adopted by this project. Since the top zones are
TABLE 5: Belt truss and outrigger floor in the prototype.

\begin{tabular}{llc}
\hline Zone & Belt truss floor & Outriggers \\
\hline Zone 1 & Floor 8 to 9 & \\
Zone 2 & Floor 17 to 19 & \\
Zone 3 & Floor 29 to 30 & \\
Zone 4 & Floor 40 to 42 & Yes \\
Zone 5 & Floor 52 to 54 & \\
Zone 6 & Floor 64 to 66 & \\
Zone 7 & Floor 76 to 78 & Yes \\
Zone 8 & Floor 88 to 90 & Yes \\
Zone 9 & Floor 101 to 103 & Yes \\
Zone 10 & Floor 112 to 113 & \\
Zone 11 & Floor 123 to 125 & \\
Zone 12 & Floor 136 to 137 &
\end{tabular}

TABle 6: Dimension of the prototype outrigger.

\begin{tabular}{lc}
\hline & Dimension $(\mathrm{mm})$ \\
\hline Height & 8000 \\
Span & 9800 \\
Chord bar & $1000 \times 800 \times 80 \times 80$ \\
Web bar & $1100 \times 1000 \times 100 \times 100$ \\
\hline
\end{tabular}

used as hotels, the wind vibration acceleration limit is $0.25 \mathrm{~m} / \mathrm{s}^{2}$.

Wind load can be considered a stationary stochastic process. In the calculation, the root mean square of the acceleration time history is multiplied by the peak factor to evaluate the peak acceleration. In this case, the peak factor is 2.5. The calculation shows that the peak acceleration of the uncontrolled structure reaches $0.36 \mathrm{~m} / \mathrm{s}^{2}$ under a 10 -year wind load, as shown in Figure 20, which exceeds the limit of $0.25 \mathrm{~m} / \mathrm{s}^{2}$ of the code.

The numerical analysis parameters are listed as follows. The time history analysis method is Fast Nonlinear Analysis (FNA). The force and energy convergence tolerances (relative) are both $1 \mathrm{e}-5$. The maximum iteration limit is 100 . The damping ratio of the original structure is 0.02 . The time 


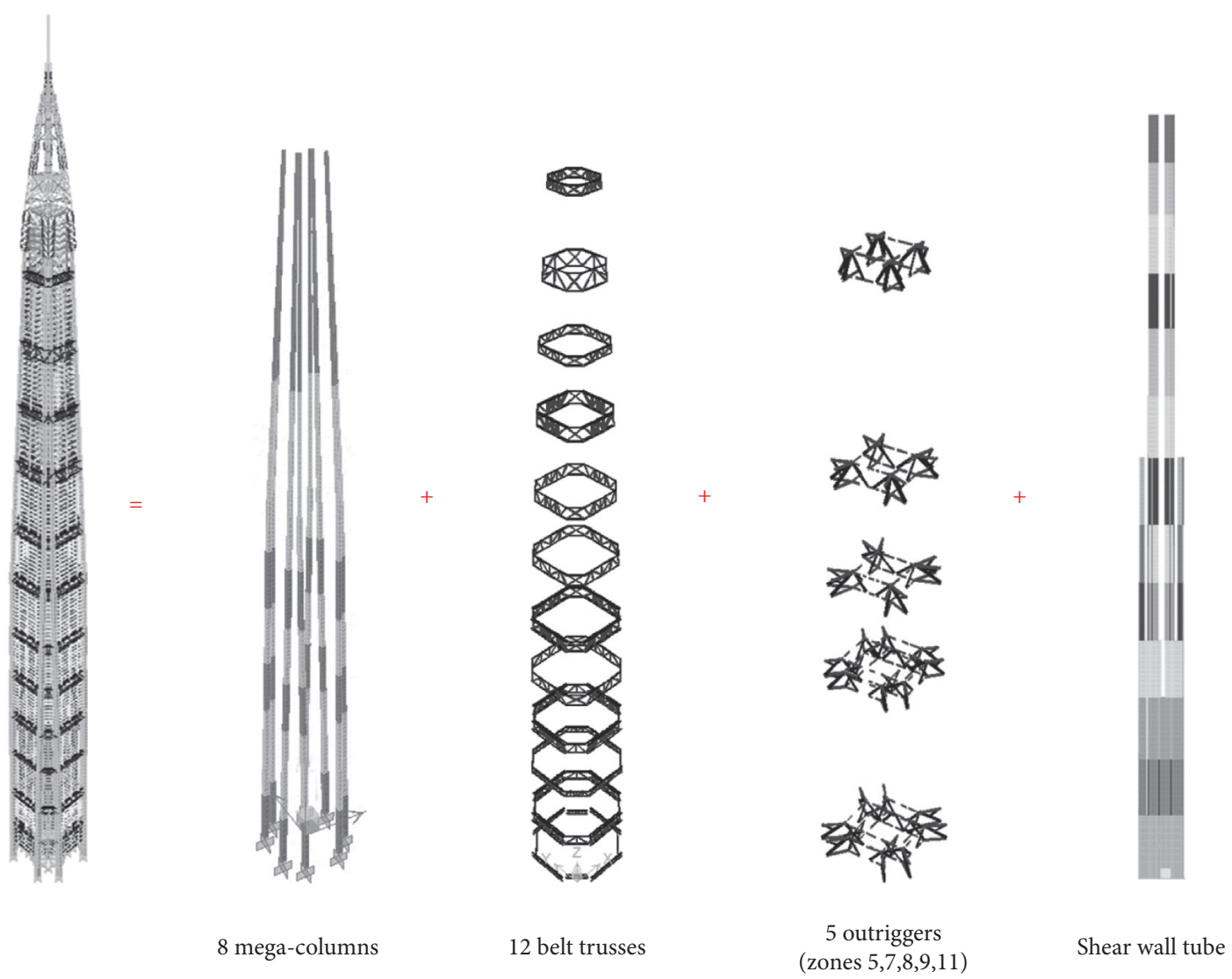

Figure 19: Typical floor plan: (a) f42 plan (zone 4); (b) f66 plan (zone 6); and (c) f101 plan (zone 9).

TABLE 7: Dimension of the prototype wall.

\begin{tabular}{|c|c|c|c|c|}
\hline \multirow{2}{*}{ Zone } & \multicolumn{2}{|c|}{ Thickness of the wall $(\mathrm{mm})$} & \multicolumn{2}{|c|}{ Width of the wall $(\mathrm{mm})$} \\
\hline & Flange wall & Web wall & Flange wall & Web wall \\
\hline Zone 12 & 450 & 450 & 3150 & 14600 \\
\hline Zone 11 & 500 & 500 & 3500 & 19500 \\
\hline Zone 10 & 600 & 600 & 4200 & 19500 \\
\hline Zone 9 & 700 & 700 & 4900 & 19500 \\
\hline Zone 8 & 800 & 800 & 5600 & 19500 \\
\hline Zone 7 & 800 & 800 & 5600 & 33400 \\
\hline Zone 6 & 850 & 850 & 5950 & 33400 \\
\hline Zone 5 & 900 & 900 & 6300 & 33400 \\
\hline Zone 4 & 900 & 900 & 6300 & 33400 \\
\hline Zone 3 & 950 & 950 & 6650 & 33400 \\
\hline Zone 2 & 1000 & 1000 & 7000 & 33400 \\
\hline Zone 1 & 1050 & 1050 & 7350 & 33400 \\
\hline
\end{tabular}

history input and output both have 10000 point at equal intervals of $0.55 \mathrm{~s}$.

\subsection{Simplified Model of Wind-Induced Human Comfort} Prediction. The walls, columns, and outriggers in the prototype should be correspondingly simplified to walls, columns, and beams in the simplified model.
The column and wall members are easy to simplify because the size is the same as the prototype. The dimensions are reported in Table 9.

For the beam members, the area without an outrigger is simplified as a rigid bar with both ends released as hinges. The outrigger is simplified as a concrete beam member. According to the method mentioned above, the cantilever end vertical deformation is $8 \mathrm{~mm}$, and the back-calculated 
TABle 8: Prototype mega-column.

\begin{tabular}{|c|c|c|c|c|}
\hline \multirow{2}{*}{ Zone } & \multicolumn{2}{|c|}{ Dimensions of the mega-column } & \multicolumn{2}{|c|}{ Distance between the mega-column and wall } \\
\hline & Length $(\mathrm{mm})$ & Width $(\mathrm{mm})$ & In plane $(\mathrm{mm})$ & Out of plane $(\mathrm{mm})$ \\
\hline Zone 12 & 1800 & 1800 & 15000 & 9500 \\
\hline Zone 11 & 2200 & 2200 & 17200 & 11500 \\
\hline Zone 10 & 2400 & 2400 & 19500 & 12500 \\
\hline Zone 9 & 2600 & 2600 & 21000 & 14000 \\
\hline Zone 8 & 3000 & 2700 & 23000 & 15300 \\
\hline Zone 7 & 3500 & 2900 & 23500 & 15300 \\
\hline Zone 6 & 4100 & 3000 & 25000 & 16700 \\
\hline Zone 5 & 4600 & 3100 & 27000 & 16700 \\
\hline Zone 4 & 5000 & 3100 & 29000 & 16700 \\
\hline Zone 3 & 5000 & 3200 & 31000 & 16700 \\
\hline Zone 2 & 5000 & 3550 & 33000 & 16700 \\
\hline Zone 1 & 5200 & 3700 & 33400 & 16700 \\
\hline
\end{tabular}

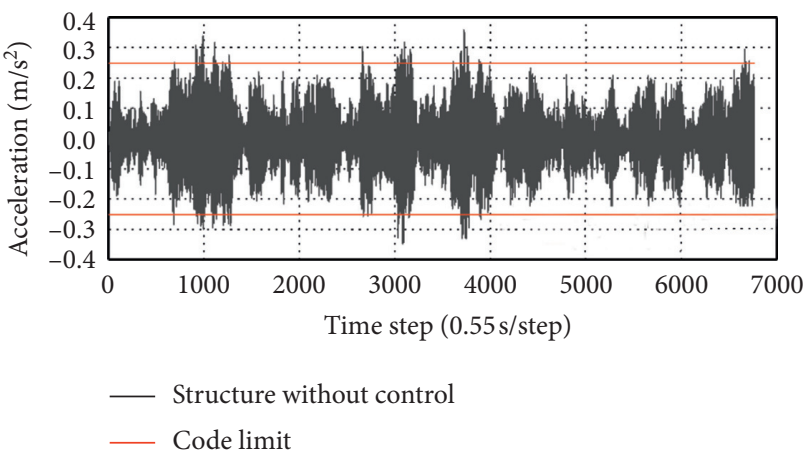

FIGURE 20: Time history of the top acceleration in the structure without control.

TABLE 9: Column and wall dimensions of the simplified model.

\begin{tabular}{|c|c|c|c|c|c|c|c|}
\hline \multirow{2}{*}{ Zone } & \multicolumn{2}{|c|}{ Wall thickness (mm) } & \multicolumn{2}{|c|}{ Wall width $(\mathrm{mm})$} & \multicolumn{3}{|r|}{ Mega-column } \\
\hline & Flange wall & Web wall & Flange wall & Web wall & Length $(\mathrm{mm})$ & Width $(\mathrm{mm})$ & Distance between the column and wall (mm) \\
\hline Zone 12 & 450 & 450 & 3150 & 14600 & 1800 & 1800 & 15000 \\
\hline Zone 11 & 500 & 500 & 3500 & 19500 & 2200 & 2200 & 17200 \\
\hline Zone 10 & 600 & 600 & 4200 & 19500 & 2400 & 2400 & 19500 \\
\hline Zone 9 & 700 & 700 & 4900 & 19500 & 2600 & 2600 & 21000 \\
\hline Zone 8 & 800 & 800 & 5600 & 19500 & 3000 & 2700 & 23000 \\
\hline Zone 7 & 800 & 800 & 5600 & 33400 & 3500 & 2900 & 23500 \\
\hline Zone 6 & 850 & 850 & 5950 & 33400 & 4100 & 3000 & 25000 \\
\hline Zone 5 & 900 & 900 & 6300 & 33400 & 4600 & 3100 & 27000 \\
\hline Zone 4 & 900 & 900 & 6300 & 33400 & 5000 & 3100 & 29000 \\
\hline Zone 3 & 950 & 950 & 6650 & 33400 & 5000 & 3200 & 31000 \\
\hline Zone 2 & 1000 & 1000 & 7000 & 33400 & 5000 & 3550 & 33000 \\
\hline Zone 1 & 1050 & 1050 & 7350 & 33400 & 5200 & 3700 & 33400 \\
\hline
\end{tabular}

bending stiffness of the outrigger is $\mathrm{EI}=3.926 \times 10^{11} \mathrm{~N} \times \mathrm{m}^{2}$. Assuming that the height-towidth ratio is 2 in the simplified model, the beam size will be $4200 \times 2100 \mathrm{~mm}$. The truss in the prototype is simplified as the concrete beam presented in Table 10 .

According to the member sizes in the above table, the simplified model can be constructed. The FEM model is shown in Figure 21.

The reduction factor of the load, mass, and damping coefficient is another key parameter in the simplified model
Table 10: Dimension of the beam in the simplified model.

\begin{tabular}{lcc}
\hline $\begin{array}{l}\text { Cantilever end } \\
\text { vertical } \\
\text { displacement }(\mathrm{mm})\end{array}$ & $\begin{array}{c}\text { Back-calculated } \\
\text { bending stiffness } \\
\left(\mathrm{N} \cdot \mathrm{m}^{2}\right)\end{array}$ & $\begin{array}{c}\text { Beam size of the } \\
\text { concrete beam in the } \\
\text { simplified model }(\mathrm{mm})\end{array}$ \\
\hline 8 & $3.926 \times 10^{11}$ & $4200 \times 2100$ \\
\hline
\end{tabular}

in addition to the member size. As the simplified model is only one slice of the prototype, the structure stiffness is smaller, and the deformation under the same load will be 


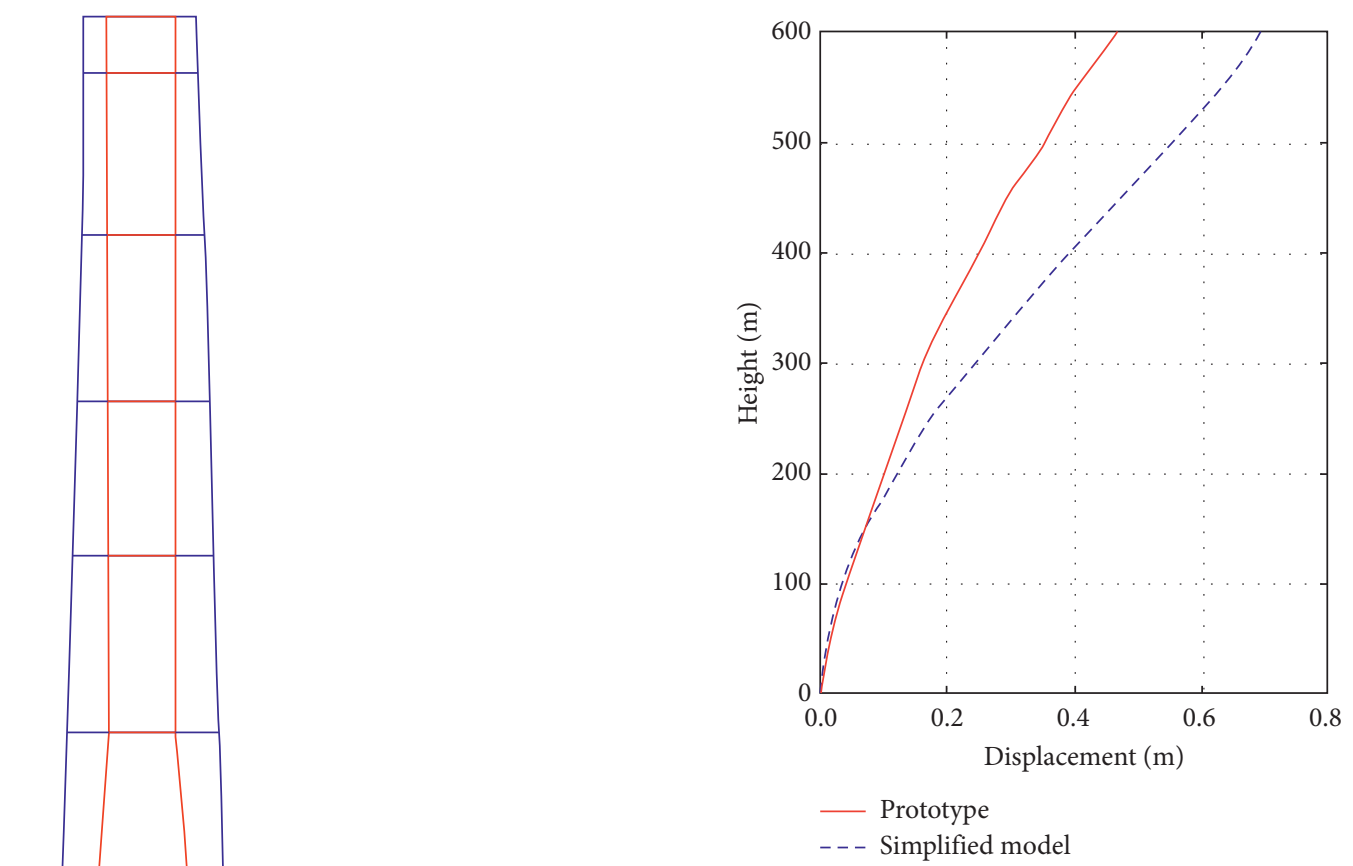

FIgURE 22: Deformation under a static load.

TABLE 11: The vertex acceleration of the prototype and simplified model $\left(\mathrm{m} / \mathrm{s}^{2}\right)$.

\begin{tabular}{lcc}
\hline Location of the damped outrigger & Prototype & Simplified model \\
\hline None & 361.9 & 360.0 \\
Zone 4 & 308.5 & 315.0 \\
Zone 6 & 319.9 & 330.8 \\
Zone 10 & 335.1 & 343.2 \\
\hline
\end{tabular}

only 12 stories, so the prototype data are extracted from the corresponding belt truss floors. Figure 22 shows that the ratio of the top point displacement of the two models is 0.66 . Therefore, the reduction factor of the stiffness, load, mass, and damping coefficient is 0.66 .

5.3. Comparison and Verification of the Wind-Induced Acceleration Prediction Accuracy of the Simplified Model. To demonstrate the applicability of the simplified model in the analysis of the vibration control of the damped outrigger system, two dampers are arranged at the end of each outrigger in zones 4, 6, and 10 with a damper exponent of 0.3 and a damping coefficient of $500 \mathrm{kN} /(\mathrm{mm} / \mathrm{s})^{0.3}$. Wind load time history analysis is performed to compare the peak acceleration, which is presented in Table 11 and Figure 23. The maximum accelerations at the top of the two models are similar to each other and have a consistent trend, which indicates that the simplified model can be used to optimize the analysis of the damped outrigger system.

FIgURE 21: FEM of the simplified model in SAP2000.

larger. The stiffness reduction factor relative to the prototype model is the ratio of the story displacement of the two models under the same static load. The simplified model has

5.4. Optimization of the Damped Outrigger System. The sensitivity vector algorithm (SVA) introduced in this paper can help designers rapidly determine the most favorable arrangement of the damped outrigger. In this building, only 


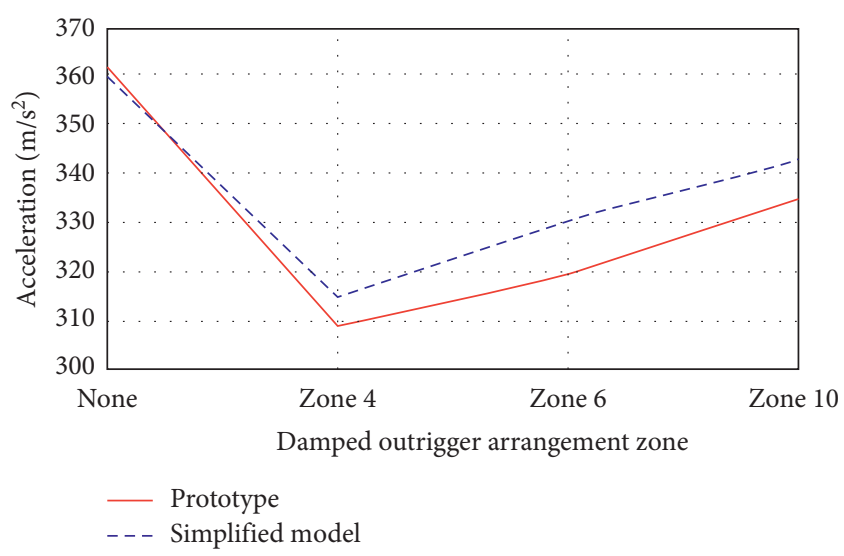

FIGURE 23: The vertex acceleration of the prototype and simplified model.

the vertex acceleration must be considered, so the target story acceleration matrix $\mathbf{a}_{\mathbf{i}}$ and $\mathbf{r}_{\mathbf{i}}$ can be simplified as scalars. The $\mathbf{r}_{\mathbf{i}}$ values can be calculated through data from Table 11 and are presented in Table 12.

The results suggest that the location of the outrigger at zone 4 is the most efficient one at reducing the vertex acceleration. Then, the sensitivity scalar can be calculated easily according to formula (8). The favorable arrangement of the damped outrigger was obtained, as listed in Table 13. Table 13 also presents that with the damping coefficient of $500 \mathrm{kN} /(\mathrm{mm} / \mathrm{s})^{0.3}$, the vertex peak acceleration cannot meet the code limit, so a damping coefficient of $700 \mathrm{kN} /(\mathrm{mm} / \mathrm{s})^{0.3}$ is used in the actual optimization.

According to the damping efficient sequential, we can arrange the dampers on the simplified model by a trial and error method to check this SVA method. First, one damper is arranged with a damping coefficient of $700 \mathrm{kN} /(\mathrm{mm} / \mathrm{s})^{0.3}$ on each end of the outrigger in zone 4 . The acceleration is reduced to $0.349 \mathrm{~m} / \mathrm{s}^{2}$, which still exceeds the code limit. A second damper is added on each end of the outrigger in zone 4. Now, the acceleration is reduced to $0.292 \mathrm{~m} / \mathrm{s}^{2}$, which still exceeds the code limit. Then, another damper is added to each end of the damped outrigger in zone 6 . The iteration is continued to the $4^{\text {th }}$ iteration until the peak acceleration of the structure vertex is smaller than the code limit. However, the cost of the damping system is proportional to the damping coefficient, and we can see that the optimization continues until the acceleration meets exactly the code limit $0.25 \mathrm{~m} / \mathrm{s}^{2}$.

After the iteration, two dampers with a damping coefficient of $665 \mathrm{kN} /(\mathrm{mm} / \mathrm{s})^{0.3}$ at each end of the damped outrigger in zone 4 and zone 6 , which is 16 dampers in each direction or 32 dampers in total, can reduce the acceleration to $0.25 \mathrm{~m} / \mathrm{s}^{2}$ to meet the code limit. The top acceleration iteration is shown in Figure 24. Table 14 presents the location, number, and damping coefficient during each step of the iteration. A comparison of the structure vertex acceleration with and without damped outriggers is shown in Figure 25.

Figure 26 shows the hysteresis loops of zones 4 and 6 after the iteration, and it can be observed that both the
TABle 12: Sensitive vector (scalar) of each damped outrigger location.

\begin{tabular}{lcc}
\hline $\begin{array}{l}\text { Location of the damped } \\
\text { outrigger }\end{array}$ & $\begin{array}{c}\text { Vertex peak acceleration } \mathrm{a}_{\mathrm{i}} \\
\left(\mathrm{mm} / \mathrm{s}^{2}\right)\end{array}$ & $r_{i}$ \\
\hline- & 360.0 & 1 \\
Z4 & 315.0 & 0.875 \\
Z6 & 330.8 & 0.916 \\
Z10 & 343.2 & 0.953 \\
\hline
\end{tabular}

TABLE 13: Favorable arrangement of the outrigger with certain numbers.

\begin{tabular}{lcc}
\hline $\begin{array}{l}\text { Most efficient } \\
\text { location }\end{array}$ & $r_{i, j, k}$ & $\begin{array}{c}\text { Estimated vertex peak acceleration } a_{\mathrm{i}} \\
\left(\mathrm{m} / \mathrm{s}^{2}\right)\end{array}$ \\
\hline-- & 1 & 0.360 \\
$\mathrm{Z} 4$ & 0.875 & 0.315 \\
$\mathrm{Z} 4,6$ & 0.802 & 0.89 \\
$\mathrm{Z} 4,6,10$ & 0.764 & 0.275 \\
\hline
\end{tabular}

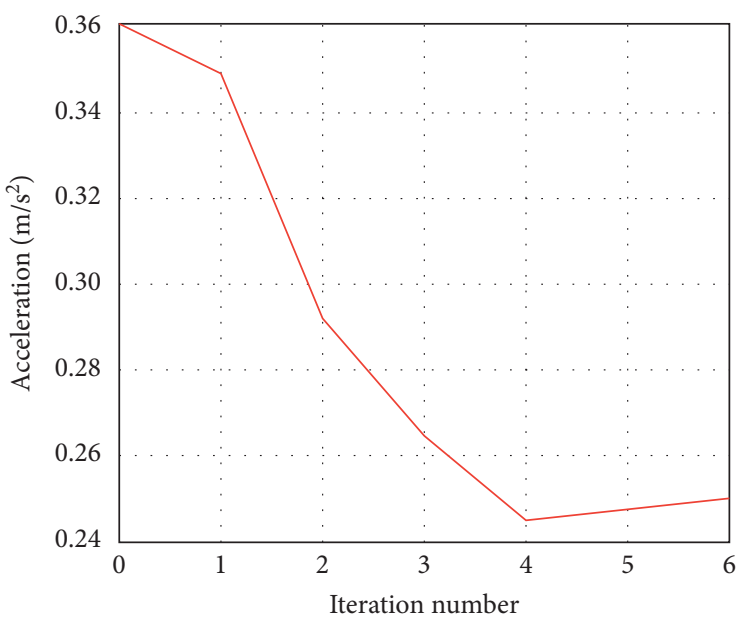

FIgURE 24: Iteration of vertex peak acceleration.

displacement and output of zone 4 are greater than those of zone 6.

5.5. Verification of the Damped Outrigger Optimal Design Method. To verify the prediction accuracy of the simplified model, the same iteration process of damped outrigger location, damper number, and damping coefficient is performed on the prototype, as reported in Table 15. Table 16 and Figure 27 present the contrast of the vertex peak acceleration of the first four iteration steps, in which the parameters of the prototype and simplified model are exactly the same. The error between the two models is less than $10 \%$ among the five sets of comparative data. The simplified model has few differences from the prototype, which means that the simplified model can accurately predict the vertex peak acceleration.

Finally, after 7 iterations on the prototype, the damped outriggers are arranged in zones 4 and 6 with two dampers 
TABle 14: Location, number, and damping coefficient during each step of the iteration (simplified model).

\begin{tabular}{lccccc}
\hline $\begin{array}{l}\text { Iteration } \\
\text { number }\end{array}$ & $\begin{array}{c}\text { Arrangement } \\
\text { zone }\end{array}$ & $\begin{array}{c}\text { Damper number at } \\
\text { each outrigger }\end{array}$ & $\begin{array}{c}\text { Damping coefficient in } \\
\text { the simplified model } \\
\left(\mathrm{kN} /(\mathrm{mm} / \mathrm{s})^{0.3}\right)\end{array}$ & $\begin{array}{c}\text { Damping coefficient in the } \\
\text { prototype model }\left(\mathrm{kN} /(\mathrm{mm} / \mathrm{s})^{0.3}\right)\end{array}$ & $\begin{array}{c}\text { Vertex peak } \\
\text { acceleration }\left(\mathrm{m} / \mathrm{s}^{2}\right)\end{array}$ \\
\hline 0 & & & & 700 & 0.360 \\
\hline 1 & 4 & 1 & 462 & 700 & 0.349 \\
\hline 3 & 4 & 2 & 462 & 700 & 0.292 \\
\hline 4 & 4 & 2 & 462 & 700 & 0.264 \\
\hline 5 & 6 & 1 & 462 & 700 & 0.245 \\
\hline 6 & 4 & 2 & 462 & 686 & \\
\hline
\end{tabular}

Note. 0 is for the structure without a damper.

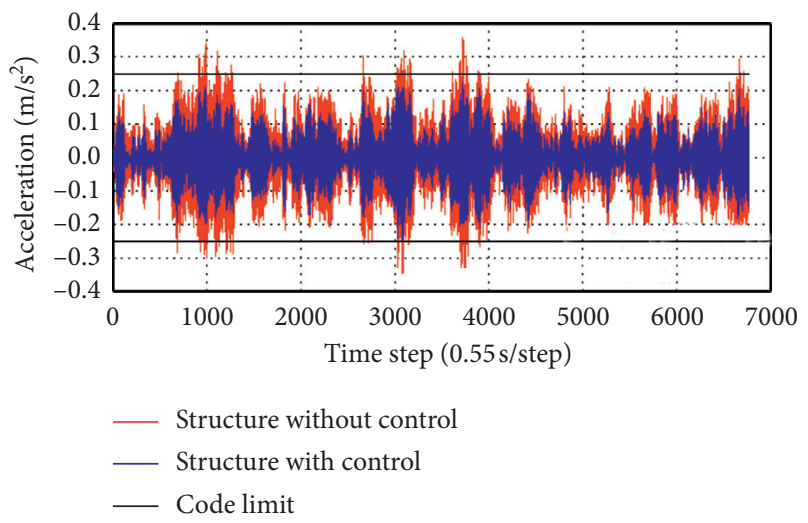

FIGURE 25: Comparison of the structure vertex acceleration with and without damped outriggers.

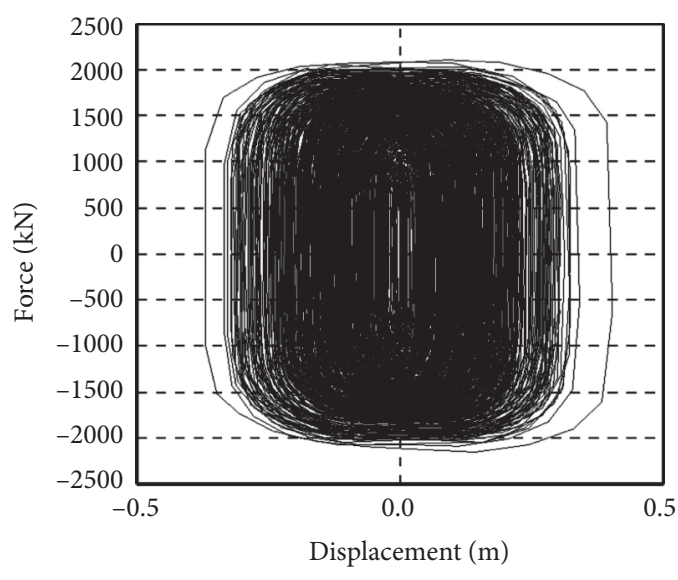

(a)

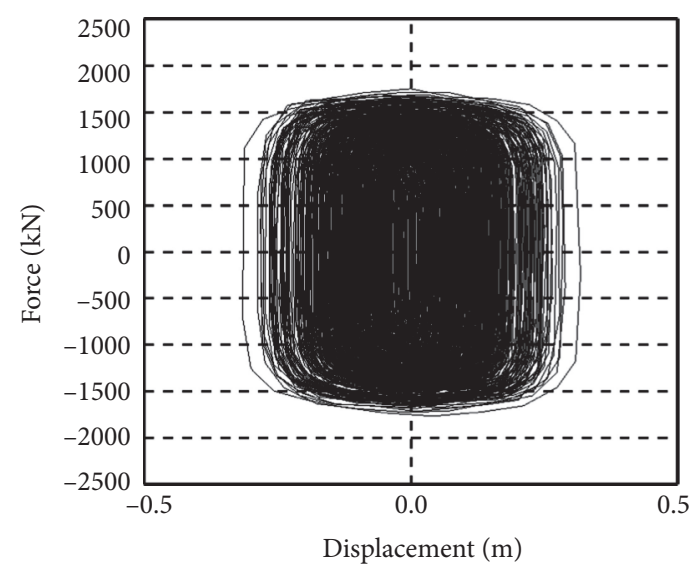

(b)

FIgURE 26: Hysteresis loops of zones 4 and 6 after iteration: (a) zone 4; (b) zone 6. 
TABLE 15: Location, number, and damping coefficient during each step of the iteration (the prototype model).

\begin{tabular}{|c|c|c|c|c|}
\hline $\begin{array}{l}\text { Iteration } \\
\text { number }\end{array}$ & $\begin{array}{l}\text { Arrangement } \\
\text { zone }\end{array}$ & $\begin{array}{l}\text { Damper number in } \\
\text { total }\end{array}$ & $\begin{array}{l}\text { Damping coefficient in prototype model (kN/ } \\
\left.\qquad(\mathrm{mm} / \mathrm{s})^{0.3}\right)\end{array}$ & $\begin{array}{l}\text { Vertex peak acceleration } \\
\left(\mathrm{m} / \mathrm{s}^{2}\right)\end{array}$ \\
\hline 0 & - & - & - & 0.362 \\
\hline 1 & 4 & 8 & 700 & 0.323 \\
\hline 2 & 4 & 16 & 700 & 0.308 \\
\hline 3 & $\begin{array}{l}4 \\
6\end{array}$ & $\begin{array}{c}16 \\
8\end{array}$ & $\begin{array}{l}700 \\
700\end{array}$ & 0.258 \\
\hline 4 & $\begin{array}{l}4 \\
6 \\
\end{array}$ & $\begin{array}{l}16 \\
16 \\
\end{array}$ & $\begin{array}{l}700 \\
700 \\
\end{array}$ & 0.242 \\
\hline 5 & $\begin{array}{l}4 \\
6 \\
\end{array}$ & $\begin{array}{l}16 \\
16 \\
\end{array}$ & $\begin{array}{l}678 \\
678 \\
\end{array}$ & 0.245 \\
\hline 6 & $\begin{array}{l}4 \\
6 \\
\end{array}$ & $\begin{array}{l}16 \\
16 \\
\end{array}$ & $\begin{array}{l}633 \\
633 \\
\end{array}$ & 0.251 \\
\hline 7 & $\begin{array}{l}4 \\
6\end{array}$ & $\begin{array}{l}16 \\
16\end{array}$ & $\begin{array}{l}635 \\
635\end{array}$ & 0.249 \\
\hline
\end{tabular}

Note. 0 is for the structure without a damper. The number is the total number for the two orthogonal directions.

TABLE 16: The vertex peak acceleration of prototype and the simplified model.

\begin{tabular}{lccc}
\hline Iteration number & Prototype $\left(\mathrm{m} / \mathrm{s}^{2}\right)$ & Simplified model $\left(\mathrm{m} / \mathrm{s}^{2}\right)$ & Error $(\%)$ \\
\hline 0 & 0.362 & 0.360 & 0.6 \\
1 & 0.323 & 0.349 & 8.0 \\
2 & 0.308 & 0.292 & 5.2 \\
3 & 0.258 & 0.264 & 2.3 \\
4 & 0.242 & 0.245 & 1.2 \\
\hline
\end{tabular}

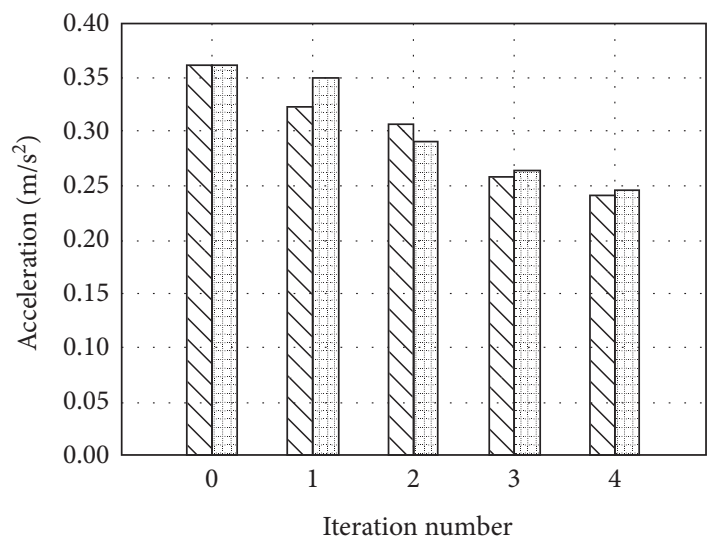

Prototype

Simplified model

FIGURE 27: The vertex peak acceleration of prototype and simplified model.

on the end of each outrigger and a damping coefficient of $635 \mathrm{kN} /(\mathrm{mm} / \mathrm{s})^{0.3}$. Moreover, the optimal design of the simplified model yields a solution in which the damped outriggers are also arranged in zones 4 and 6 with two dampers on each end of the outrigger and a damping coefficient of $665 \mathrm{kN} /(\mathrm{mm} / \mathrm{s})^{0.3}$. The dampers have the same location and number of damped outriggers, and the difference in the damping coefficient is only $4.7 \%$.

In addition to the accuracy, the simplified model has significantly improved the iteration efficiency. During the design process, every iteration requires a recalculation of the wind time history. It usually takes 2-3 hours for each nonlinear calculation process with a large amount of DOFs and 6-7 iterations for each optimization, and it takes 2-3 days to complete the design of the damped outrigger system. While the simplified model has a much smaller number of DOFs, the time of each iteration calculation will be greatly reduced. In this case, the calculation process of each iteration takes approximately 3 minutes using the simplified model. Considering the simplified process from the prototype model to the simplified acceleration prediction model, the total time to complete the design of the damped outrigger system using the simplified acceleration prediction model is 3-4 hours.

\section{Conclusions}

This study presents a simplified model for predicting windinduced human comfort of supertall buildings and an optimal design method for viscous damped outrigger systems based on this model. Taking a practical supertall as an example, the accuracy of the simplified model for predicting wind-induced vibration human comfort and the efficiency of the optimal design method for a viscous damped outrigger system based on the simplified model are illustrated. The main conclusions are as follows:

(1) Based on the mechanical characteristics of the megaframe core wall structure and the characteristics of the viscous damped outrigger system connected to the main structure, a simplified model for predicting 
wind-induced human comfort of a supertall building is proposed in this study. The main lateral resisting members of the supertall, wall, and column are taken as the components of the simplified model, and in this manner, the complex three-dimensional supertall model is simplified to a simple two-dimensional plane model while retaining the deformation characteristics of the supertall. Through the derivation of the dynamic equation, the key factor affecting the accuracy of the acceleration prediction results of the simplified model is that the period and mode shapes of the simplified model are consistent with those of the original model, and the reduction factors of the load, mass, and damping coefficients are consistent with that of the stiffness. The analysis shows that the dynamic characteristics of the structure are insensitive to the error in the simplified component size.

(2) An optimal design method based on the simplified acceleration prediction model is proposed. This method can obtain the optimal placement of a viscous damped outrigger, the optimal number of dampers, and the optimal damping coefficient of the dampers under the constraint condition of structure comfort and the minimum system cost.

(3) The optimization process mainly includes the optimization stage of the location and number of viscous dampers with fixed viscous damping coefficients and the optimization process of viscous damping coefficients after the location and quantity are determined. The optimization stage of the number and location employs the sensitivity vectors algorithm. The optimization assumptions and constraints are proposed according to actual engineering conditions.

(4) Taking a supertall building as an engineering case and adopting the optimization design proposed in this study, the accuracy of the simplified model and the efficiency of the optimization design method are verified. This method can obtain the optimal parameters, improve the design efficiency, reduce the project cost, and conserve social resources.

\section{Data Availability}

The analysis data used to support the findings of this study are included within the article.

\section{Conflicts of Interest}

The authors declare that they have no conflicts of interest regarding the publication of this paper.

\section{Authors' Contributions}

Y. Yang was responsible for conceptualization and writing. JY. Li performed conceptualization. X. Zhao and WX. Shi provided supervision.

\section{Acknowledgments}

The authors are grateful for the support from the Shanghai Excellent Discipline Leader Program (no. 14XD1423900).

\section{References}

[1] L. Wang, X. Zhao, and Y. M. Zheng, "A combined tuned damper and an optimal design method for wind-induced vibration control for super tall buildings," The Structural Design of Tall and Special Buildings, vol. 25, 2016.

[2] D. Y. Wang, Y. S. Zhang, and Y. Zhou, "Study on occupant comfort evaluation mode of tall buildings in wind excitation based on fuzzy probability method," The Structural Design of Tall and Special Buildings, vol. 26, 2017.

[3] A. Tallin and B. Ellingwood, "Serviceability limit states: wind induced vibrations," Journal of Structural Engineering, vol. 110, no. 10, pp. 2424-2437, 1984.

[4] Y. Zhou and L. Xing, "Seismic performance evaluation of a viscous damper-outrigger system based on response spectrum analysis," Soil Dynamics and Earthquake Engineering, vol. 142, 2021.

[5] Q. Wang, H. Qiao, D. de Domenico, Z. Zhu, and Z. Xie, "Wind-induced response control of high-rise buildings using inerter-based vibration absorbers," Applied Sciences (Switzerland), vol. 9, 2019.

[6] D. de Domenico, H. Qiao, Q. Wang, Z. Zhu, and G. Marano, "Optimal design and seismic performance of Multi-Tuned Mass Damper Inerter (MTMDI) applied to adjacent high-rise buildings," The Structural Design of Tall and Special Buildings, vol. 29, 2020.

[7] L. Wang, W. Shi, X. Li, Q. Zhang, and Y. Zhou, "An adaptivepassive retuning device for a pendulum tuned mass damper considering mass uncertainty and optimum frequency," Structural Control and Health Monitoring, vol. 26, pp. 1-21, 2019.

[8] L. Wang, W. Shi, and Y. Zhou, "Study on self-adjustable variable pendulum tuned mass damper," The Structural Design of Tall and Special Buildings, vol. 28, 2019.

[9] R. J. Smith and M. R. Willford, "The damped outrigger concept for tall buildings," The Structural Design of Tall and Special Buildings, vol. 16, 2007.

[10] Z. Lu, X. He, and Y. Zhou, "Performance-based seismic analysis on a super high-rise building with improved viscously damped outrigger system," Structural Control and Health Monitoring, vol. 25, 2018.

[11] X. He and Z. Lu, "Seismic fragility assessment of a super tall building with hybrid control strategy using IDA method," Soil Dynamics and Earthquake Engineering, vol. 123, pp. 278-291, 2019.

[12] Y. Zhou and H. Li, "Analysis of a high-rise steel structure with viscous damped outriggers," The Structural Design of Tall and Special Buildings, vol. 23, 2014.

[13] J. Ding, S. Wang, and H. Wu, "Seismic performance analysis of viscous damping outrigger in super high-rise buildings," The Structural Design of Tall and Special Buildings, vol. 27, 2018.

[14] M. Morales-Beltran, G. Turan, U. Yildirim, and J. Paul, "Distribution of strong earthquake input energy in tall buildings equipped with damped outriggers," The Structural Design of Tall and Special Buildings, vol. 27, 2018.

[15] J. C. O'Neill, Application of Damping in High-Rise Building, Massachusetts Institute of Technology, Cambridge, MA, USA, 2006. 
[16] Y. Chen, D. M. McFarland, Z. Wang, B. F. Spencer, and L. A. Bergman, "Analysis of tall buildings with damped outriggers," Journal of Structural Engineering, vol. 136, no. 11, pp. 1435-1443, 2010.

[17] P. Tan, C. J. Fang, C. M. Chang, B. F. Spencer, and F. L. Zhou, "Dynamic characteristics of novel energy dissipation systems with damped outriggers," Engineering Structures, vol. 98, pp. 128-140, 2015.

[18] B. Huang and T. Takeuchi, "Dynamic response evaluation of damped-outrigger systems with various heights," Earthquake Spectra, vol. 33, no. 2, pp. 665-685, 2017.

[19] K. Deng, P. Pan, A. Lam, and Y. Xue, "A simplified model for analysis of high-rise buildings equipped with hysteresis damped outriggers," The Structural Design of Tall and Special Buildings, vol. 23, 2014.

[20] B. S. Smith and I. Salim, "Parameter study of outrigger-braced tall building structures," ASCE Journal of Structural Division, vol. 107, 1981.

[21] B. S. Taranath, "Optimum belt truss locations for high-rise structures,” Engineering Journal, vol. 11, 1974.

[22] X. Lu, X. Lu, H. Sezen, and L. Ye, "Development of a simplified model and seismic energy dissipation in a super-tall building," Engineering Structures, vol. 67, pp. 109-122, 2014.

[23] M. M. Ali and K. S. Moon, "Advances in structural systems for tall buildings: emerging developments for contemporary urban giants," Buildings, vol. 8, 2018.

[24] M. Gu and Y. Quan, "Across-wind loads of typical tall buildings," Journal of Wind Engineering and Industrial Aerodynamics, vol. 92, no. 13, pp. 1147-1165, 2004.

[25] China Ministry of Construction (CMC), Technical Regulations for Concrete Structures of High-Rise Buildings (JGJ3-2010), China Architecture \& Building Press, Beijing, China, (in Chinese), 2010.

[26] China Ministry of Construction (CMC), Code for Seismic Design of Buildings (GB 50011-2010), China Architecture \&Building Press, Beijing, China, (in Chinese), 2010.

[27] S. P. Timoshenko and J. N. Goodier, Theory of Elasticity, McGraw-Hill, New York, NY, USA, 1970.

[28] Alan R.. Klembczyk. http://www.teratec.ca/wp-content/ uploads/Utilizing-Damping-Devices_to_Improve_Resiliency_ of_Structures.pdf.

[29] H. S. Choi, G. Ho, L. Joseph, and N. Mathias, Outrigger Design for High-Rise Buildings, Routledge, Miton, UK, 2017. 